\title{
Adolescent family life education: Review of curriculum
}

Ladly Faiz

Hasina Banu

Devi Sharma

Follow this and additional works at: https://knowledgecommons.popcouncil.org/departments_sbsr-pgy

Part of the Family, Life Course, and Society Commons, and the International Public Health Commons How does access to this work benefit you? Let us know!

\section{Recommended Citation}

Faiz, Ladly, Hasina Banu, and Devi Sharma. 1996. "Adolescent family life education: Review of curriculum," Special Report. Dhaka: Population Research and Development Associates and Population Council. 


\title{
ADOLESCENT FAMILY LIFE EDUCATION: REVIEW OF CURRICULUM
}

\author{
Final Report
}

Ladly Faiz, Ph.D

Hasina Banu, M.S

Devi Sharma, Ph.D

\section{Population Research and Development Associates (PRDA)}

\&

\section{The Population Council}

\author{
Asia and the Near East Operations Research \\ and Technical Assistance Project
}

This project was supported by the Population Council's Asia and the Near East Operations Research and Technical Assistance (ANE OR/TA) Project. The ANE OR/TA Project is funded by the US Agency for International Development, Office of Population, under Contract No.DPE-3030-C00-0022-00, Strategies for Improving Family Planning Service Delivery. 


\section{PREFACE}

Population Council requested Population Research and Development Associates to review the present status of Adolescent Family Life Education program and curricula of government and non-government organizations in Bangladesh. The main objective of this report was to collect information on 'Adolescent Family Life Education' program and curricula status in Bangladesh. For this purpose different government and non-government organizations were visited and the officers directly related with the AFLE program were interviewed. Afterwards a report was prepared based on this evaluation.

\section{TABLE OF CONTENTS}

\section{Page No.}

Preface $\quad$ i

1. Chapter one: Adolescent Family Life Education (AFLE) 1-3 Program

1. Introduction $1-2$

1.1 Background 2

1.2 Objective of Evaluation $\quad 2-3$

1.3 Methodology Explanation

2. Chapter two: Role of Government, Non-government and Donor Agencies in Implementation of Adolescent Family Life Education Program

2.0 Introduction 5-6

2.1 Integrated Non-formal Education Expansion Program(INFEP) 6-12

2.2 Voluntary Health Services Society (VHSS) 13-14

2.3 Bangladesh Population and Health Consortium(BPHC) 14-15

2.4 The Ford Foundation (FF)

\section{Chapter three: Condition of AFLE Programs and Curricula 16-52}

3.0 Description of Programs of Different Organizations

3.1 Family Planning Association of Bangladesh(FPAB)

3.2 Family Planning Services and Training Center(FPSTC)

3.3 Center for Development Services(CDS)

3.4 Family Development Services and Research(FDSR) 
3.5 International Center for Diarrhoeal Research(ICDDR,B)

3.6 Under Privileged Children's Education

Program (UCEP),Bangladesh

3.7 Center for Mass Education(CMES)

$39-42$

3.8 Bangladesh Rural Advancement Committee(BRAC)

$42-45$

3.9 Dhaka Ahsania Mission(DAM)

$46-47$

3.10 World Vision(WV), Bangladesh

47-51

3.11 Concerned Women for Family Planning(CWFP)

$51-52$

4. Chapter four: Evaluation of AFLE Curriculum Used by

$53-65$ Different Organizations

5. Chapter five: Conclusion 66-69

6. Book-list

$70-74$

7. Appendix: 1, 2, 3, 4, 5 .

75-91 


\section{Chapter One}

\section{ADOLESCENT FAMILY LIFE EDUCATION PROGRAM}

\section{Introduction}

Adolescents are about 23 percent of the total population of Bangladesh. They are entitled to grow up as healthy and responsible members of the society. In our country, Adolescent Life Education program has been started in order to ensure the rights of this large section of population and to develop them as healthy and responsible members of the family and society.

Adolescent Life Education (ALE) is internationally known as family life education. This is a relatively new concept and its incorporation in the education sphere of Bangladesh is a very recent phenomenon. Adolescents in all society learn their responsibilities towards their family and elderly by observing and following the behavior of others. Due to rapid social change all over the world, the young generation is presently facing an enormous problem in coping with the erosion of traditional family, social life, and values. Under this environment adolescent family life education can help the adolescents especially in the transition from childhood to youth.

This report evaluates the present condition of the Adolescent Family Life Education program and curricula of government and non-government organizations working in Bangladesh. The primary objective of this report was to develop an Adolescent Family Life Education curriculum for USAID funded NGOs on the basis of evaluation results so that in future they can use the same type of curricula for implementation of the program.

\subsection{Background}

The education that provides knowledge on physical, mental, social, moral, behavioral, and mentality changes and developments during puberty is generally called Adolescent Family Life Education. It teaches the adolescents about the role of boys and girls in family and society, responsibility and attitude of boys and girls towards one another etc. within our social context.

\section{Objectives of Adolescent Life Education}

Adolescents will learn through this education-

- To be mentally, physically, and socially confident in attaining self-sufficiency.

- To cope with the physical as well as mental changes that take place during puberty.

- To be aware of the STDs. Many may become victims of STDs in the adolescent stage due to ignorance. This can create severe personal health problems and may eventually 
lead to grave social hazards. Moreover, one will learn to safe-guard one-self and the society from its curse.

To behave responsibly with the members of the family and be conscious about the social, individual, and personal rights and well-being.

- To establish healthy human relations in the sphere of family, society and work-arena.

- To develop new points of view concerning life and to use values for directing the codes of law.

- To take correct and logical decisions regarding the family, self and social life in terms of values.

Adolescents are very curious by nature, can easily adapt new ideas, learn quickly, and also apply their knowledge. So the appropriate time of learning about adolescent life is the adolescent stage itself.

\subsection{Objective of evaluation}

The primary objective of this report is to investigate, collect and review the written materials in the form of books, reports, journals on ALE by visiting different organizations and in this context observe the status of the present 'Adolescent Life Education' program and curricula status in Bangladesh.

\section{Specific objectives:}

1. Identification of the organizations connected with the Adolescent Family Life Education program in Bangladesh.

2. Description of the type, background and activities of AFLE program of different organizations.

3. Description of the present status of the AFLE program in Bangladesh.

4. Application and the state of Adolescent Family Life Education curricula.

5. Description and identification of the central issues addressed by Adolescent Life Education curricula and program. 


\subsection{Methodological explanation:}

To fulfil the objectives, the evaluation team visited a total of 24 organizations. Among them, 4 were government and 20 were non-government organizations. At the time of the inspection, separate discussions on this subject were held with officers of the organizations and the personnel directly involved with the AFLE program. Names of the officers and the organizations are enclosed in the appendix (appendix no. 2). Among the inspected organizations 13 had prepared their own curriculum (10 NGOs, 1 government and 1 AFLE forum/VHSS and 1 donor agency) for the program.

The evaluating team collected information from all the inspected organizations during 1st August-30th August, 1995 and used a questionnaire to elicit the necessary information. This is enclosed at the appendix (appendix no. 5).

The evaluating team after evaluating the collected information discussed the present status of the 'Adolescent Life Education' program and its curricula in Bangladesh. For review purpose the team collected and compiled books, reports etc. of different countries on 'AFLE' program and curricula. This has been attached in the appendix under the heading of booklists (appendix no. 3). 


\section{Chapter Two}

\section{ROLES OF GOVERNMENT, NON-GOVERNMENT, AND DONOR AGENCIES IN THE IMPLEMENTATION OF THE AFLE PROGRAM}

\subsection{Introduction:}

At present many organization are working with the AFLE program in Bangladesh. Only a few years ago, people hesitated to talk openly about AFLE program. The beginning of nineties marked a new phase for the AFLE program in Bangladesh as the government, nongovernment and donor agencies at that time began to give special emphasis on this education program and started working with it along with their other programs.

This chapter discusses the program and curricula of four organizations. These organizations provided grants and technical assistance to other organizations to integrate AFLE program with their main programs.

This report the describes the programs of each organization along with their own/or adopted curricula that they followed for ALE program so that the emphasis laid by them on different subjects in the curricula can be easily observed.

In this chapter we will discuss about the following four organizations:

1. Integrated Non-formal Education Expansion Program (INFEP)

2. Voluntary Health Services Society (VHSS)

3. Bangladesh Population and Health Services (BPHC)

4. The Ford Foundation (FF)

Information about programs of these four organizations are listed below in Table-1. 
Table 1

Summary of Program Activities

\begin{tabular}{|c|c|c|c|c|c|}
\hline $\begin{array}{c}\text { Name of } \\
\text { Organization } \\
\end{array}$ & Main Program & $\begin{array}{r}\text { Beginning } \\
\text { of AFLE } \\
\text { program }\end{array}$ & $\begin{array}{l}\text { Boys/ } \\
\text { Girls }\end{array}$ & $\begin{array}{l}\text { Age } \\
\text { range/ } \\
\text { level }\end{array}$ & $\begin{array}{l}\text { Curriculum } \\
\text { prepared by }\end{array}$ \\
\hline $\begin{array}{l}\text { 1. Integrated Non- } \\
\text { formal Education } \\
\text { Expansion } \\
\text { Program (INFEP) }\end{array}$ & $\begin{array}{l}\text { Endowment of basic literacy } \\
\text { ('shakharata') through non- } \\
\text { formal instruction system. }\end{array}$ & 1993 & Both & $11-14$ & Self \\
\hline $\begin{array}{l}\text { 2. Voluntary } \\
\text { Health Services } \\
\text { Society (VHSS) }\end{array}$ & $\begin{array}{l}\text { Coordinating agency, } \\
\text { providing technical assistance } \\
\text { for coordination between local, } \\
\text { regional and national level } \\
\text { NGOs working in health } \\
\text { related activities. }\end{array}$ & 1991 & Girls & $9-19$ & Self \\
\hline $\begin{array}{l}3 . \quad \text { Bangladesh } \\
\text { Population and } \\
\text { Health Services } \\
(\text { BPHC) }\end{array}$ & $\begin{array}{l}\text { Providing financial and } \\
\text { technical assistance to small } \\
\text { and medium NGOs for } \\
\text { maternal and child health } \\
\text { related activities. }\end{array}$ & 1989 & Girls & $12-16$ & Self \\
\hline $\begin{array}{l}\text { 4. Ford } \\
\text { Foundation (FF) }\end{array}$ & $\begin{array}{l}\text { Providing financial and } \\
\text { technical assistance for social } \\
\text { development, constructive } \\
\text { change, reproductive health, } \\
\text { human development and in } \\
\text { other fields. }\end{array}$ & 1991 & Girls & $9-18$ & * \\
\hline
\end{tabular}

* FF provided grants to VHSS and CMES to develop a curriculum in 1991.

\subsection{Integrated Non-formal Education Expansion Program (INFEP) Primary Mass Education Section, Dhaka.}

The primary objective of the main program of this organization is to inspire the illiterate adolescents- to become literate and to provide basic literacy ('shakharata') through non-formal instruction system. In 1993, INFEP developed a new curriculum by incorporating some key issues that are related to the lives of the adolescents.

The objectives of the new curriculum are: to attain basic literacy and apply it in daily life, to acquire necessary knowledge and skill for future profession selection, to know the role and condition of adolescents in family and society, and development of values, and to acquire necessary knowledge and skill for qualitative improvement of life. 
Initially an integrated non-formal education program was started in 69 thanas under this organization for adolescents of 11-14 years. The duration of this education expansion program was two years.

\section{Description of Curriculum}

Non-formal education program can play a very important role in inspiring the adolescents of 11-14 years to attain literacy and encourage them to participate in social and economic activities. So far, different curricula have been used to implement the ALE program. These are: (1) adolescent study (part 1, 2, \& 3): teacher's guide; and (2) adolescent study (part 1, $2, \& 3)$. The crucial issues relating to adolescent life such as society, life, mental and physical changes during puberty, future activities and certain environmental issues are presented also. The discussed topics are consistent with the age and acceptance abilities of the students and are portrayed through beautiful illustrations and stories. The description of the main topics discussed under these five subjects are given below:

Economics: $\quad$ Work and income; farming methods; easy income earning ways; small business; fish farming; handicrafts; poultry farming; fruit plantation; formation of capital and its use; project planning and management; letter writing; application and filling up forms; preservation of food grains; account of family incomeexpenditure.

Society, country and culture:

Behavior of adolescents:

Health and Environment:

Laws, rights and responsibilities:
Family; neighbor; society; responsibilities and duties; family environment; account of the country; honor and dignity of women in the society; male-female relation; organization and co-operative.

Characteristics of adolescents; games and physical exercises; mental and physical changes of adolescents; team work.

Cleanliness; safe water; maintenance of family health;

diseases; superstitions; types and elements of environment; care of environment; improved hearth; first-aid treatment; mother and child; vaccination and prevention of diseases; population and planned family.

Rights; relationship between responsibility and law; family and social rights of the adolescents; wage and share-cropping law; child-labor; law enforcing institutions; family law; human rights; female rights; social laws. 


\subsection{Voluntary Health Services Society (VHSS)}

This organization co-ordinates and assists NGOs operating in health related activities at the local, regional, and national level of the country.

In order to fulfil the requirements of the adolescents, VHSS and BPHC together created a new forum called AFLE in 1991. From the inception of the forum VHSS worked as its secretariat. The main task of this secretariat is to spread AFLE throughout the country and to co-ordinate the AFLE related programs of different organizations.

Various organizations participated actively in AFLE forum, which include Bangladesh Rural Advancement Committee (BRAC), Bangladesh Population and Health Consortium (BPHC), Bangladesh Women's Health Coalition (BPHC), Concerned Women for Family Planning (CWFP), Jatiya Tarun Sangha (JTS), Family Development Services and Research (FDSR), Family Child Development Institute (FCDI), Sechchasebi Bohumukhi Mohila Samaj Kalyan Sangstha (SBMSS), Center for Mass Education (CMES), The Asia Foundation (TAF), Concerned Women's forum/Naripakha. Later on, many organizations joined the program of the AFLE forum. At present, the forum has 61 members. Table 2 provides detailed description of its members.

Table 2

Membership situation of AFLE forum across different divisions

\begin{tabular}{||c|c|l||}
\hline Division & Number of members & Name of organization \\
\hline Dhaka & 31 & $\begin{array}{l}\text { OMI, VIWF, BSSBG, FDSR, DMSS, } \\
\text { FPAB, ASOD, CDS, MJSS, CWFP, } \\
\text { AEEB, TAF, AIDB, JTS, TDHS, NM, } \\
\text { BWHC, MCI, CMES, AAF, NUS, FCHD, } \\
\text { PRODIPON, PRDA, BPHC, UTPS, } \\
\text { MSBO, RDRS, STC, AESA, FPSTC. }\end{array}$ \\
\hline Khulna & 11 & $\begin{array}{l}\text { VIDA, BSKS, JC, JJS, GUD, AWC, SNS, } \\
\text { MSS, SEDAB, AIESDEUP, GJSKS. }\end{array}$ \\
\hline Chittagong & 2 & CDC, FCDI. \\
\hline Rajshahi & 12 & $\begin{array}{l}\text { BS, BJ, TVWO, TMSS, UDP, GUA, CW, } \\
\text { FP Rajshahi, SBMSS, JKS, BPS, SU. }\end{array}$ \\
\hline Barisal & 3 & PPC, RDS, DAB. \\
\hline
\end{tabular}

* Full name of the organizations are given in appendix 1.

AFLE forum started working through 5 sub-committees, namely

(i) education and communication committee, 
(ii) curriculum committee,

(iii) information committee,

(iv) field and research committee, and

(v) advisory committee.

The Information, education and communication sub-committee at the beginning of the forum conducted an investigation on materials used by different organizations and schools to promote AFLE and prepared a list of those. The Curriculum sub-committee on the other hand, realized the need for producing a necessary and suitable education curriculum for the adolescents in the context of Bangladesh. The advisory sub-committee through a survey analyzed the knowledge of adolescents about diarrhoea, family planning, complex physical changes and related problems during adolescent stage. The Field and research sub-committee collected information on AFLE programs of different organizations in Bangladesh. On the basis of all this information, a two-day workshop was held for the first time in June 1992, with the assistance from BPHC, the Asia Foundation, and Unicef. BPHC provided the first financial grant for implementation of this program.

The specific objectives of the first workshop were: age determination of the adolescents (9-19 years), deciding on ALE curriculum, future plan, and holding of seminars at the national level.

With the financial grants from BPHC, a national level seminar was held in July 1993. The objectives of the seminar were: to create consciousness among the general public about the importance of AFLE concept and program, discuss and review the AFLE curricula, and to share experiences of the VHSS AFLE forum with other organizations.

To make the AFLE program effective among the interested voluntary institutions, VHSS, in 1994 conducted 4 regional and 1 national discussion meetings. The regional meetings were held in Barisal, Chittagong, Jessore and Rajshahi. A national workshop was held in Dhaka where Miss. Indu Kapoor (Executive Director, Chetona, Ellahabad, Gujrat) from India was present as special guest. The objectives of this workshop were to: present the AFLE program to government and NGOs; present recommendations of the 4 regional meetings; exchange AFLE experience of other nations; present an AFLE curriculum and encourage other organizations to use it.

In the national workshop, group discussions were held on four issues. These are:

(1) plan of Adolescent Family Planning program;

(2) method of popularizing Adolescent Family Life Education program;

(3) assistance in the implementation of the Adolescent Family Life Education program;

(4) constraints in the way of implementation of Adolescent Family Life Education program.

The specific decisions regarding future AFLE program that were undertaken in the national workshop are:

(1) AFLE is needed to be integrated with programs of other organizations; 
(2) VHSS will provide the necessary assistance to those organizations who are interested to implement the AFLE program;

(3) AFLE program has to be consistent with culture, values etc. of the country;

(4) VHSS as AFLE forum member-secretary, will coordinate and assist the government, voluntary organizations and donor agencies.

In October 1994, a survey titled `Assessment of Adolescent Family Life Education programs in Bangladesh' was conducted with assistance from VHSS. The primary objective of the survey was to identify the organizations presently working on AFLE and to encourage other organizations to integrate this program with their existing programs. The first phase of the AFLE program ended in December 1994. An internal evaluation was done in 1995. The main objective of the evaluation was to test the extent of the first phase AFLE program of the forum and take decisions regarding its future program plan. The assistance from Human Resource Development division enabled VHSS to make arrangements for training 24 trainers of 23 organizations. A separate curriculum was developed for this training purpose.

Arrangements were made through the forum for conducting study tours in India in 1994. The places visited were : Child in new institute, Calcutta; family service center, New Delhi; and Chetona, Elahabad, Gujrat.

\section{Description of curriculum}

The curriculum was developed by the combined efforts of AFLE forum members and VHSS. At present, many organizations are using this curriculum besides their own program. Many have selected different issues from this curriculum according to their own program needs and over 50 members are interested to use it.

The family life education curriculum for adolescents has been divided into two chapters. The first chapter is used to train the trainers and the second one contains three modules which are: (a) social consciousness;

(b) reproductive health and population education; and

(c) primary health-care.

Thirty topics are discussed in these three modules. The highest emphasis is placed on social consciousness which consists of fourteen subjects. Each of the other two modules contains 8 topics. The following section discusses in details the subjects of the above mentioned curriculum. 
1. 'Family Life Education Curriculum for Adolescents'

\section{Part 1:}

Manual for trainers:

(a) what is family life education and why is it necessary;

(b) why adolescents need to be trained;

(c) rules for forming groups by adolescents;

(d) some tips for the trainers;

(e) methods of providing training;

(f) necessary training methods;

(g) rules for adolescent life education session.

\section{Part 2:}

3 Modules-

\section{Module 1:}

Social Consciousness

(a) Patriotism and civic responsibilities;

(b) responsibilities towards parents;

(c) values and character formation;

(d) friendly relations among boys and girls;

(e) mutual dependency;

(f) household management;

(g) behavioral discrimination towards boys and girls;

(h) mental health and emotional problems;

(i) honor and dignity of women;

(j) dowry;

(k) child marriage;

(l) polygamy;

(m) divorce and marriage separation;

(n) female oppression.

\section{Module-2:}

Reproductive Health and Population Education

(a) Changes of boys and girls during puberty;

(b) female-male reproductive system;

(c) menustration and mystery of birth;

(d) role of mother and father in sex determination of the child;

(e) sexually transmitted diseases;

(f) sexual harassment;

(g) population education;

(h) family planning and its necessity.

\section{Module 3:}


Primary Health-Care
(a) Diarrhoea;
(b) vaccination;
(c) intestinal worms;
(d) personal cleanliness and healthy habits;
(e) breast milk for baby;
(f) blindness due to malnutrition;
(g) nutrition for adolescents;
(h) problems of iodine deficiency.

2. Illustrated Report on Adolescent Life Education (Issues discussed below are presented through illustrations)

(a) Changes of boys and girls during puberty;

(b) female-male reproductive system;

(c) menustration and mystery of birth;

(d) role of mother and father in sex determination of the child;

(e) sexually transmitted diseases/HIV;

(f) education on population;

(g) what is family planning and why is it required;

(h) diarrhoea;

(i) vaccination;

(j) intestinal worms;

(k) cleanliness and healthy habits;

(l) breast milk for baby;

(m) blindness due to malnutrition;

(n) nutrition for adolescents;

(o) problems of iodine deficiency.

3. Guide for Adolescent Life Education- Training of trainers

Training is provided through six modules.

\section{Module 1:}

(a) Inaugural session;

(b) adolescent life education.

Module 2:

(a) Procedure of training and idea about training;

(b) training and education;

(c) determination of training requirements.

\section{Module 3:}


(a) Methods of training;

(b) role of training in participatory method.

\section{Module 4:}

(a) Develop communication;

(b) elements;

(c) encouragement.

\section{Module 5:}
(a) Curriculum and lesson plan;
(b) presentation of group work;
(c) evaluation;
(d) report and documentation.

\section{Module 6:}

(a) Different formats used in training;

(i) introduction sit;

(ii) knowledge test letter/format;

(iii) feedback format for presenter;

(iv) evaluation of VHSS training course;

(v) follow-up report;

(vi) completion report format.

4. ALE for adolescents (Booklet)

(a) Adolescent life from 9-19 years;

(b) physical growth;

(c) change in voice;

(d) muscles;

(e) what happens during puberty;

(f) time of puberty;

(g) how the changes start in the puberty stage;

(h) other changes;

(i) pubic hair; armpit hair; physical hair;

(j) beard;

(k) breast; reproductive nerve of females; menustration;

(l) male reproductive organs, sexual activities, sexual intercourse;

(m) sexual intercourse and pregnancy;

(n) venereal diseases;

(o) contraceptive systems;

(p) food; exercise;

(q) smoking, drinking alcohol and drug abuses;

(r) cleanliness;

(s) discipline. 
A list of publications (books, seminar report, booklet etc.) made by VHSS, AFLE forum is provided below:

FLE curriculum for adolescents

FLE Booklet for adolescents

FLE-Guide for training trainers

FLE-illustrated report, flip chart calendar form

Wall chart (2), boys and girls

Assessment report of AFLE program in Bangladesh

Seminar report on 'ALE' 14th and 15th July, 1993

AFLE: Regional and national meeting 1994, report

Evaluation report on AFLE

\subsection{Bangladesh Population and Health Consortium (BPHC)}

BPHC provides small and medium NGOs with grants and technical assistance for MCH-FP program from 1988. The financial assistance from BPHC led to the commencement of the AFLE program between 1989 to 1993. This project was started experimentally in 5 NGOs. They are: SBMSS- Rajshahi, FDSR-Dhaka, CWFP-Rajshahi, CWFP-Bhoirab, and Narimaitry-Dhaka. BPHC is carrying out non-formal AFLE program for the girls of 12-16 years age group in these projects through cards which record gradual growth of the adolescent girls. The cards are kept in the respective residences of the participants.

The main objective of the program is to raise consciousness of the adolescent girls about the mental and physical changes that occur during puberty.

- Keep a monthly record of height, weight, date of first menustration, monthly menustration cycle and illness of adolescent girls.

- Make the adolescent girls conscious about the importance of maintaining gradual growth list.

- Make the underweight and below 4 feet 10 inches women aware of high risks at pregnancy.

- Encourage the 15 year old adolescent girls to take 2 doses of preventive TT.

- Provide education on general and reproductive health.

These organizations felt the special need to develop a curriculum for implementation of the above program. Up until 1992, no curriculum on mental and physical changes during puberty was available in Bengali language in Bangladesh. On the other hand, VHSS curriculum was also not published in the planned time. The curriculum then became very important for program need and necessity. Later on BPHC held a workshop with assistance from CWFP, SBMSS, and FDSR. In this workshop, curriculum guidelines in the form of 'necessary knowledge of adolescent life' were determined by BPHC. A consultant developed this 
curriculum for BPHC in 1992. The description of the issues discussed in the curriculum are provided below.

\section{Description of Curriculum}

'Necessary Knowledge of adolescent life'

1. What is AFLE; how does AFLE help; objectives of AFLE.

2. Puberty: Physical changes during puberty; mental and emotional changes during puberty; reasons for mental and physical changes during puberty.

3. Changes of girls: Change of breasts; breast development; breast-care; growth of pubic hair; external female sex organ; internal female sex organ; menustration; reasons for menustration; necessary steps to be taken at times of menustration; things to be remembered at times of menustration; menopause; hymen.

4. Physical changes of boys: External and internal changes of boys and girls; wet dream; mental changes of boys and girls.

5. Noticeable issues for adolescents.

6. Pregnancy: When can girls become pregnant; how girls become pregnant; symptoms of pregnancy; care of pregnant women; serious problems during pregnancy; things to be avoided by the pregnant women; preparation of safe delivery; measures to be followed by the pregnant women; risk of pregnancy at young age; sterility.

7. Family planning and birth control: What is family planning; need of family planning; family planning adoption ways; detailed description of family planning methods; temporary methods; oral birth control pill; birth preventive injections; NORPLANT; copper-T (IUD); Temporary birth control methods-condom; foam tablet; menustration regulation (MR). Permanent methods-vasectomy; ligation. Natural birth control methods- abstinence; withdrawal; rhythm or safe-period; traditional wrong notions about family planning; effectiveness of the methods of family planning.

8. Sexually transmitted diseases: Story of Firoz; gonorrhea; syphilis; AIDs.

9. Food and nutrition in the adolescent stage: Nutrition and balanced diet.

10. Personal health-care: Dental care; eye care; hair care and nail care; intestinal worms; immunization or disease preventive vaccination; injection; diarrhoea; safe water and sanitary latrine.

The curriculum of BPHC offers a detailed explanation of the physical and emotional changes in boys and girls during puberty. Besides, pregnancy for adolescent girls, problems that may arise in pregnant condition and necessary measures for overcoming these problems, safe delivery, sterility and menopause related topics are discussed. Another important side of this 
curriculum is that it discusses sexually transmitted diseases. Sexual education and consciousness development of adolescents is a necessary prerequisite for avoiding these diseases. This curriculum has been used by many organizations. They are: FDSR; SBMSS; CWFP-Bhoirab; Rajshahi-Narimaitry; VHSS and TDH.

\subsection{The Ford Foundation (FF)}

This organization from the beginning of 60's has been providing financial and technical assistance to Bangladesh for working in different fields like development of political, legislative and administrative services for less privileged general public, constructive changes in social development through services of voluntary organizations, and services and research assistance for research, reproductive health, human development etc.

Ford Foundation has been providing grants to 2 organizations for implementation of AFLE program in Bangladesh. These organizations are: Voluntary Health and Services Society (VHSS) and Center for Mass Education in Science (CMES). VHSS from its inception has received different types of assistance from Ford Foundation. This organization received grants from July 1993 to December 1994 to run the AFLE program. CMES has also received grants from the same source for the period 1991-1997 to run AFLE program through primary mass education. 


\section{Chapter Three}

\section{STATE AND APPLICATION OF ADOLESCENT LIFE EDUCATION PROGRAM IN NON-GOVERNMENT ORGANIZATIONS}

\subsection{Description of Programs Undertaken By Various Organizations:}

In Bangladesh various organizations have started adolescent life education program along with their main programs at different times. Even though the program was implemented on primary basis, the responses from the adolescent boys and girls were remarkable in the project areas.

This chapter reviews in details the programs of 11 non-government organizations and their curricula (prepared by themselves or by others) for adolescent life education program. The discussion includes only those organizations that follow self-prepared curriculum. The names of the organizations are listed below:

1. Family Planning Association of Bangladesh (FPAB)

2. Family Planning Services and Training Center (FPSTC)

3. Center For Development Services (CDS)

4. Family Development Services and Research (FDSR)

5. Urban Health Extension Project (UHEP), International Center for Diarrheal Diseases Research, Bangladesh (ICDDR, B)

6. Under Privileged Children s Education Program (UCEP), Bangladesh

7. Center for Mass Education in Science (CMES)

8. Bangladesh Rural Advancement Committee (BRAC)

9. Dhaka Ahsania Mission (DAM)

10. World Vision (WV), Bangladesh

11. Concerned Women for Family Planning Program (CWFP)

The main programs of these organizations are presented in the following Table. 
Table 3

Main programs of eleven organizations and the State of their curriculum

\begin{tabular}{|c|c|c|c|c|c|}
\hline $\begin{array}{l}\text { Name of } \\
\text { Organization }\end{array}$ & Main-Program & $\begin{array}{c}\text { Beginning } \\
\text { of AFLE } \\
\text { Program }\end{array}$ & $\begin{array}{l}\text { Boysl } \\
\text { Girls }\end{array}$ & $\begin{array}{l}\text { Age-limitl } \\
\text { Class }\end{array}$ & $\begin{array}{l}\text { Curriculum - } \\
\text { Prepared By }\end{array}$ \\
\hline 1. FPAB & $\begin{array}{l}\text { Family Planning, } \\
\text { Maternal and } \\
\text { Child health }\end{array}$ & 1977 & $\begin{array}{l}\text { Boys } \\
\text { Girls }\end{array}$ & $\begin{array}{l}15-30 \\
15-25\end{array}$ & Self and others \\
\hline 2. FPSTC & $\begin{array}{l}\text { Family Planning, } \\
\text { Maternal and } \\
\text { Child health }\end{array}$ & 1992 & Girls & $9-19$ & Self \\
\hline 3. CDS & $\begin{array}{l}\text { Family Planning, } \\
\text { Maternal and } \\
\text { Child health }\end{array}$ & 1993 & Girls & $\begin{array}{l}\text { class VIII- } \\
\text { class X }\end{array}$ & Self \\
\hline 4. FDSR & $\begin{array}{l}\text { Social-welfare } \\
\text { programs and } \\
\text { Family Planning }\end{array}$ & 1985 & $\begin{array}{l}\text { Girls } \\
\text { Boys }\end{array}$ & $\begin{array}{l}12-16 \\
15-25\end{array}$ & Self \\
\hline $\begin{array}{l}\text { 5. UHEP, } \\
\text { ICDDR,B }\end{array}$ & Research & 1990 & Girls & $12-20$ & Self \\
\hline $\begin{array}{l}\text { 6. UCEP, } \\
\text { Bangladesh }\end{array}$ & $\begin{array}{l}\text { Non-formal } \\
\text { Education }\end{array}$ & 1973 & $\begin{array}{l}\text { Boys } \\
\text { Girls } \\
\end{array}$ & $\begin{array}{l}\text { class I- } \\
\text { Class V } \\
\end{array}$ & Self \\
\hline 7. CMES & $\begin{array}{l}\text { Non-formal } \\
\text { Primary } \\
\text { Education }\end{array}$ & 1991 & Girls & $11-19$ & Self \\
\hline 8. BRAC & $\begin{array}{l}\text { Non-formal } \\
\text { Primary } \\
\text { Education }\end{array}$ & 1988 & Girls & $1-14$ & Self \\
\hline $\begin{array}{l}\text { 9. Ahsania } \\
\text { Mission }\end{array}$ & $\begin{array}{l}\text { Non-formal } \\
\text { Education }\end{array}$ & 1992 & $\begin{array}{l}\text { Girls } \\
\text { Boys }\end{array}$ & $\begin{array}{l}11-17 \\
11-17 \\
\end{array}$ & Self \\
\hline $\begin{array}{l}\text { 10. World } \\
\text { Vision, } \\
\text { Bangladesh }\end{array}$ & Formal Education & 1992 & Girls & $9-18$ & Self \\
\hline 11. CWFP & $\begin{array}{l}\text { Family Planning, } \\
\text { Maternal and } \\
\text { Child health }\end{array}$ & 1991 & Girls & $13-15$ & Self \\
\hline
\end{tabular}




\subsection{Family Planning Association of Bangladesh (FPAB)}

This organization started through different programs the youth projects along with family planning and child health-care services from 1977. The first financial aid for this project was provided by International Planned Parenthood Federation (IPPF). Since then, FPAB with the assistance from IPPF has arranged various educational programs on family planning for the impecunious youths. Moreover, it has been arranging debates for school and college students at district, division, and national levels to enhance their consciousness about the role of education, health, and family planning in family life.

A project titled Utilization of Voluntary Agencies in Population Activities is maintained with the financial assistance received from USAID, which is one of the donor agencies of FPAB. The project includes a considerable number of youth clubs. These youth clubs besides motivating for family planning, provide education on some additional topics such as population, sexual health and reproductive health, STDs, etc.

The target and objectives of youth program were fixed in 1994 in congruence with the long term (1994-2002) work strategies of FPAB. The project was named "Education on Family Life and Sex through the Youths". The main objective of the current project is to teach 5 million boys and girls (of 15-30 years age group) about topics such as- population, sex and reproductive health, STDs/AIDS, and primary health care, so that they may grow up into responsible parents in the future.

The project is implemented with the peer groups- boys of the age group 15-30 years and girls of the age group 11-25 years. The project was extended in 1994 to ten more unions besides the previously existing sixty unions in twenty branches. Nine special work units were set up for running the project.

To bring the target group under the program 1750 youths were trained as instructors. Among them, $75 \%$ were male and $25 \%$ were female. These young instructors provided idea about family and sexual education to groups consisting of those who were not enrolled in school or had dropped-out from school. Each group has 25-30 participants and meetings of these groups are held once a month in a union.

The main objective of this project is to provide complete idea about population education, family life, sex and health education to 21,000 youths through group discussions and yearly meetings.

- To provide knowledge about population education, family life, health and sex education to those who are of school going age, not enrolled in school and have dropped out from school with the active help of the youth leaders trained in seventy unions.

To teach the illiterate children and adolescents to read and write, and to perform simple calculations through ninety social-education centers. 
- To arrange, different types of games and entertainment for relaxation of the young men.

- To provide various types of vocational training to the unemployed and under employed for self-employment purpose.

- To arrange debates for the students of school and college level in order to acquaint the youths with various social problems.

- To observe various national and international days with due respect in the project areas with the help of the youth leaders.

- To carry on various social-development programs in the project areas with active participation of the youths.

- To motivate the newly married youths in family planning and to distribute contraceptives among them.

- To enlighten the youths in the project areas about planned family through various documentary films of FPAB and to distribute various books, magazines, posters of the club in school and college libraries and among the educated youths.

- To induce the youths of the project areas to take and abide by five oaths. These are:

a. marry at matured age

b. abstain from giving and receiving dowry in marriage

c. abstain from smoking, drinking and drug abuses and stand up against terrorism

d. Promote forests for maintenance of ecological balance

e. Teach at least two illiterate persons every year

\section{Description of the Curriculum}

FPAB has three curricula-

(A) Social education center guide.

(B) Illustrated guide on population education.

(C) Population education curriculum for youths not enrolled in school and dropped-out from school.

Description of the curriculum is provided in the following pages:

\section{(A) Social Education Center Guide}

Program plan of social education center (for TOT trainers): basic literacy; alphabets; writing Bengali alphabets; Bengali math; social studies; meaning and objectives of social-studies. 


\section{Family Life and Social Values:}

Types of family in Bangladesh; family activities; marriage; social values and faiths; influence of the state; family; and individuals; family budget; savings in family budget; significance of savings.

\section{Health Education:}

Meaning implied by health; importance of sound health; primary health-care and its meaning; eight components of primary health-care.

\section{Population Education:}

Definition of population; growth and decline of population; population explosion and problems faced by Bangladesh due to population growth; population control; natural population controled by man; planned family.

\section{(B) Illustrated Guide on Population Education}

Population; population dynamics; population growth in Bangladesh (population explosion); problems arising due to population growth; population growth and land area 50 years back; projection of population growth and land area after 50 years; population growth and lands; population growth and clothing; population growth and housing; population growth and medical facilities; population growth and education; population growth and child labor (educationd problem); population growth and nutrition; population growth and environment; population growth and unemployment; population growth and socio-cultural problems; natural causes of population reduction; formation of planned family; planned family; happiness and prosperity of planned family.

\section{(C) Curriculum for Youths Not Enrolled In School and Dropped Out From School}

\section{Chapter One}

Definition of population; size, composition, and stratification of population; change in population; crude birth rate and crude death rate; population growth rate; population explosion; population and family life; population control.

\section{Chapter Two}

Family- Types of family in Bangladesh; family activities; marriage; family budget; importance of religion; social, and family life; definition of religion; social values and faiths; influence of individuals; family and state; cultural changes with modernization; social and cultural problems. 


\section{Chapter Three}

Meaning of health; importance of sound health; overall health situation in Bangladesh; Diseases-various types of diseases; food and nutrition; elements of food; cleanliness; sewerage system; maternal and pregnancy care; care of new-born; baby food; importance of first-aid; objectives of first-aid; duties and responsibilities of health workers; different types of first-aid.

\section{Chapter Four}

Marriage and importance of social life; family activities; relationship between husband and wife; Contention-disagreement and altercation in the family; causes and solutions; mystery of human birth; male-female reproductive system; organs of the male reproductive system; organs of the female reproductive system; menstruation; responsible parenthood; Family planning-meaning of family planning; need for family planning program in Bangladesh and in the world; importance of population education in Bangladesh; objective of education on population; apparatus used in population education program; population education through the trained youth-leaders.

\subsection{Family Planning Services And Training Center (FPSTC)}

FPSTC provides MCH-FP services in Bangladesh. The main objective of the organization is to implement family planning program at the local level through voluntary organizations and to provide them regular financial and technical assistance.

In order to strengthen family planning and maternal and child health care services, FPSTC at the initial stage planned to start Family Life Education (FLE) program in 20 supported projects in 1992. The project was incorporated with the main program of this organization. The target group of this program is the adolescent girls. The objective of this program is to prepare the adolescent girls from their puberty for their future married life. In accordance with this objective attempts were made to enlighten the adolescent girls through non-formal education to encourage them to form small and happy families in the future. The program was launched in five areas in 1993-1994. These areas are: Narayangonj port, Brahamanbaria, Jessore, Gaibandha and Patuakhali.

Selection of the adolescent girls for FLE program was based on the following criteria: age between 9 to 19 years, unmarried, permanent resident of the project area, priority to adolescent girls not enrolled in school or dropped-out from school.

One female field supervisor/team leader was selected from every FPTSC supported project under FLE program and were trained in Dhaka office. Afterwards, these trained field supervisors arranged meeting in their own projects with the help of field workers/villageorganizers and taught the adolescent girls about family life.

A list of adolescent girls was prepared where they were divided into different groups. Each group has 20-25 members. Each month two meetings are arranged for these adolescents in 
non-formal manner. In these meetings, field supervisors provide training on ten subjects included in the FLE curriculum in 24 sessions.

\section{Objectives of FPSTC}

The female adolescent groups will acquire knowledge about family and married life and become conscious through the current AFLE program. Thus they can live a planned and happy life in the future.

\section{Description of Curriculum}

\section{Family Life Education (FLE)- Study Plan}

1. FLE related ideas: Introduction; objective; training; verification of previous knowledge.

2. Individual health-care in adolescence:

(a) Health-care: teeth; eyes; hair; nails.

(b) Intestinal worms: what are intestinal worms; how they grow; prevention and cure.

(c) Diseases and cures: Diarrhoea: what is diarrhoea; effects of diarrhoea; symptoms of diarrhoea; treatment of diarrhoea; preparation of oral saline; preparation of home made saline; instruction for using oral saline or liquid mixture of salt and molasses; when should the diarrhoea patients be taken to the doctors; causes of diarrhoea and prevention.

(d) Safe water and sanitary latrine: safe water, harmful effects of polluted water, sanitary latrines, needs for sanitary latrines, conditions of building sanitary latrines.

3. Needs for food and nutrition in adolescence:

(a) Food and nutrition: Energy producing or carbohydrate food; growth inducing or protein food; fat and oil; vitamins; mineral salts; water.

(b) Balanced diet and List of balanced diet.

4. Changes during puberty:

(a) Physical changes of females during puberty

(b) Mental and emotional changes during puberty and coping measures

(c) Physical care and changes of females

(d) Changes of breasts-breast development; breast-care; other physical changes; mental changes of boys and girls.

(e) Important issues for the adolescents: 
For the adolescent girls:

1) checking regularity of menstruation;

2) paying attention to strong belly ache during menstruation;

3) paying attention to illness or any sorts of pain;

4) drinking enough water, and not suppress urine when in pressure;

5) checking breasts once a month for clots, or reddish circles;

6) measuring height and if possible weights regularly;

7) immediately inform the elderly persons about any attempts of sexual harassment or application of force by any person rather than concealing it due to shyness or fear.

For male adolescents:

1) realize the fact that there is nothing heroic in acting the hoodlum by using drugs or smoking, rather it is seriously detrimental to health;

2) showing respect and honor towards women and refraining from applying force on them;

3) paying importance to physical illness or any sorts of pain.

5. Menstruation:

(a) what is menstruation; cause of menstruation and things to be done during this time;

(b) things to be kept in mind during menstruation;

(c) menstruation and physical and mental changes.

6. Child marriage and health:

(a) discussion on marriage and child marriage: definition of marriage; conditions of marriage; age; consent; denmohor ( the marriage portion of dower that a husband has to allot for his wife at wedding); registration.

(b) Reasons behind child marriage : relief from responsibilities; menstruation; to make new relatives and fanciful desires; tendency to marry minor aged girls; lack of scope of education; ignorance about social customs and laws; lack of education; other ignorance and superstitions.

(c) Discussion on proper age of marriage and proper time for child bearing for preservation of good health: high maternal death rates; obstacles to complete physical development of the females and other complexities; negative attitude towards sex experience; incapability to take proper care of children; underweight new born; high rates of pregnancy.

(d) Ways of preventing child marriage: to make the people conscious; increase female literacy; raise consciousness about child marriage prevention laws; poverty alleviation.

7. Mystery behind human birth:

(a) Reproductive system, important organs of male-female reproductive system;

(b) functions of reproductive system;

(c) conditions behind birth;

(d) reasons behind pregnancy, symptoms and types of pregnancy. 
8. Disease preventing vaccination/immunization:
(a) name of diseases;
(b) preventive vaccination/immunization;
(c) immunization centers.

9. Population problem and family planning:

(a) present state of population;

(b) problems;

(c) probable solution measures for the problems;

(d) family planning.

10. Family planning or birth control:

Definition of family planning; necessity of family planning; how family planning is possible; methods of family planning; effectiveness and side-effects of family planning methods.

11. Female education and its necessity:

(a) Position of women in the society;

(b) main objective of female education;

(c) formal and non-formal education;

(d) necessity of female education: for creating consciousness among the females (social, economical, religious); for developing: self-confidence, skills, income earning ways and social rights for improved life-style.

\subsection{Center For Development Studies (CDS)}

Along with family planning, maternal and child health care services and other programs CDS started adolescent life education program in five project areas on an experimental basis during 1993 with financial and technical assistance of Asia Foundation. The program started in the projects that were included in Female Education Scholarship Program assisted by Asia Foundation, and this program included specially the adolescent girls of class eight to class ten. The names of the organizations through whom CDS operates are provided below: 
Table 4

Areas of Adolescent Life Education Program

\begin{tabular}{|l|l|l|}
\hline Name of Organization & Thana & District \\
\hline $\begin{array}{l}\text { Bangladesh Association for Community } \\
\text { Education(BACE) }\end{array}$ & Sharasthi & Chadpur \\
$\begin{array}{l}\text { Maler Hat Jubo Sangha (MJS) } \\
\text { Bohu Mukhi Unnayan Society (BUS) } \\
\text { Southern Gano Unnayan Sangstha (SGS) } \\
\text { Pally Unnayan Prochestha }\end{array}$ & $\begin{array}{l}\text { Hayemchar } \\
\text { Kalkini } \\
\text { Gopalganj } \\
\text { Lohagora }\end{array}$ & $\begin{array}{l}\text { Chadpur } \\
\text { Madaripur } \\
\text { Gopalganj } \\
\text { Norayl }\end{array}$ \\
\hline
\end{tabular}

In July 1993, a new organization named Gano Kalyan Kendra (GKK) was added to this group of organizations. Inspite of exclusion from Female Scholarship Program the objective of this organization was to observe the changes that might result from continuing adolescent life education program along with family planning and maternal and child health-care services. Another group was included in the Adolescent Life Education Program. This group consisted of parents, guardians, school teachers and other community members.

The objectives of the adolescent life education program were as follows-

- To make the adolescent girls conscious about their healths enabling them to take care of themselves in the future.

- To integrate adolescent life education with family planning.

- To empower the adolescent girls in social and family life by providing them education and training.

CDS has undertaken the following agenda to implement this program:

(a) Teach the adolescent girls by the facilitator.

(b) Conduct regular meetings for the guardians in order to create consciousness about adolescent life education.

(c) Conduct regular meetings for creating consciousness about adolescent life education among the school teachers.

(d) Arrange community meetings and fairs.

(e) Make vegetable gardens.

In order to implement this program the female teachers were provided basic and refresher training.

Description of The Curriculum 
To implement the AFLE program CDS has prepared a number of curricula. The list is provided below:

1. Family life education for the adolescent girls (Instruction manual)

2. Flip chart guide on family life education.

3. The higher the number of children the higher the expenditure (booklet)

4. Inquiries of adolescence No-1. (leaflet)

5. Inquiries of adolescence No-2 (leaflet)

6. Inquiries of adolescence No-3 (leaflet)

7. Healthy family, happy life.

8. An illustrated leaflet.

\section{Description of the different curricula are provided below:}

1. 'Family life education' for the adolescent girls (instruction manual)

This contents covering on 63 topics are divided in 6 modules.

\section{Module no-1}

Family and Society

This includes 9 lessons. These are-

Family; types of family and activities of family; custom of marriage in formation of family; family relationships and roles; responsibilities towards family and family rights; family lifecycle; family assets and budget; analyzing social structure; social harmony and social-welfare activities.

\section{Module no-2}

Health and Nutrition

\section{Health:}

This module consist of 9 lessons. These are-

Basic knowledge about health; cleanliness and health education; EPI/immunization; water; sewerage system; health problems due to iodine deficiency and its prevention; mental health (for adolescents girls); maternal health; child health.

\section{Nutrition:}

There are 9 lessons on nutrition and these are as follows-

Food and types of food; functions of food and nutrition, balanced diet and source of nutrition; diseases due to malnutrition and their symptoms; food requirements in accordance with age; prevention of blindness due to malnutrition; and diseases due to iodine deficiency; prevention and cure of malnutritional anemia; nutrition for the adolescent girls.

\section{Module no-3}

Behavior and Values 
This includes 9 topics which are as follows-

Individual entity; changes during puberty; rights on own body; pre-maturity; sexual problems; sexual harassment; indecent pictures; honor and dignity of women; friendship and life-partner selection; child marriage and health.

\section{Module no-4}

Reproductive health and Education on sex

This contains 8 topics, such as-

Mystery of birth; differences in physical structure and male-female reproductive organs; reproductive organs; ovulation and menstruation cycle; pregnancy and care of pregnant women; growth of embryonic baby and preparation during delivery; sexuality and development of sexuality; pre-mature sexuality and perverted sexuality; prevention and cure of venereal diseases.

\section{Module no-5}

Law and rights

This includes 7 topics, these are-

Child marriage preventing law; marriage separation law; Muslim marriage and divorce law; denmohor and maintenance; female violence prevention law; dowry prohibition law; inheritance law.

\section{Module no-6}

Education on population

This module contains 12 topics. These are-

Population and society; population of Bangladesh and society; basic knowledge about family planning; relationship of family planning with maternal welfare and child health; vasectomy (male sterilization); tubal ligation (female sterilization); condom; birth spacing oral pills; IUD; injection as a birth control measure; NORPLANT; integrating the people with the family planning program.

\section{Family Life Education Guide}

This is a flip chart. It is mainly prepared for adolescent life education program. This contains instructions for using the flip chart which are as follows-

(a) Prior to field or class presentation one should learn the inside information and figures.

(b) One should use it only after learning the information and figures correctly and properly.

(c) Figures should be placed before the participants during presentation.

(d) The texts of the flip chart should face the presentator himselflherself. 
(e) The information contained in the chart is required to be described in own and local dialect for better understanding.

(f) The participants should be given the opportunity to respond while showing them the figures contained in the guide.

(g) The participants should be thanked for their valuable opinion.

The flip chart provides illustrated description of information concerning `society and family', such as-

(a) Family: What is a family; reasons behind depending on family and importance of family.

(b) Nuclear family: Role and characteristics of nuclear family.

(c) Extended family: Characteristics; roles and social ties.

(d) Joint family: Characteristics of joint family.

(e) Family relations: Types of family relations, behavior and role.

(f) Function of family: Role of different family members and their responsibilities according to relationships.

(g) Family life-cycle: Eight stages of family life-cycle beginning from the formation of family to the demise of either husband or wife.

(h) Demand for resources: Demand for family life-cycle based resources; classification and characteristics of family resources.

3. The Higher The Number of Children The Higher The Expenses (booklet)

The objective of this booklet is- to create consciousness about education and population growth. This contains illustrated explanation of different topics, such as- the higher the number of children the lower the opportunities of education; various problems and their solutions; family planning.

4. 'Inquiries of Adolescence' (leaflet) no-1

This contains discussion on various topics concerning physical changes of adolescents girls. These are-

a) information relating to menstruation, its time and advice concerning cleanliness;

b) hormones- Its role in physical changes of female specially in the manifestations of the adolescence and puberty; information on estrogen and progestraron. 
5. Inquiries of Adolescence no-2

The topics discussed are-

General inquiries of the adolescents: few anxious questions on physical changes of the adolescents, such as- mild pain on nipples; wet dream; growth of mustache etc.

General inquiries of the adolescent girls- Answers to questions relating to uneasiness during puberty, such as- uneasiness in movement due to growth of breasts; beginning of menstruation; measures to be followed if menstruation happens in school, etc.

6. Inquiries of Adolescence no-3

The following topics are discussed here:

Inquiries and expectations of the adolescent girls:

(a) probable time of menstruation;

(b) how to understand whether menstruation has begun; feelings during menstruation; reasons for irregularity in the first year of menstruation; menstruation cares; proper use of pads, panties etc; cleanliness and other information.

7. 'Healthy Family and Happy Life'

This contents discussion on 19 topics which are divided into 10 chapters.

Chapter-One : $\quad$ Introduction to Family Life Education program and its importance, puberty

Chapter-Two $\quad: \quad$ Society and our family life.

Chapter-Three : $\quad$ Introduction to basic laws of our daily life; marriage laws; Kabinnama (marriage contract); denmohor; divorce; dowry; polygamy; rape; abduction.

Chapter-Four $\quad: \quad$ Family planning and sex education.

Chapter-Five $\quad: \quad$ Social harmony and development in traditional customary Bangladesh.

Chapter-Six $\quad: \quad$ Health in family life; importance of environment and cleanliness.

Chapter-Seven: $\quad$ Mystery of birth; male-female reproductive system.

Chapter-Eight : $\quad$ Importance of food and nutrition in family life; nutrition for the adolescent girls.

Chapter-Nine $\quad: \quad$ Cares and cures of common illness in family life. 
Chapter-Ten $\quad: \quad$ Venereal diseases.

8. 'An Illustrated leaflet' (Single page)

This contains some topics on mother and parents, such as- the starting time of menstruation usually is 12 to 14 years. Menstruation occurs after every 28 days for an adult female. During menstruation one may experience weakness or pain in lower abdomen. Normal activities can be continued during this time. The respective parents should take appropriate care so that their female child may stay clean and take nutritious foods during menstruation.

\subsection{Family Development Services and Research (FDSR)}

This organization started functioning from 1985 through social welfare activities. The principle objectives of the organization is-to develop family as an ideal social institution, to identify the needs and problems of the family, to provide welfare services to the families through various programs so that they may fulfill their needs, and to prepare the adolescents of the family mentally and physically so that they may become worthy citizens and live prosperously. Besides welfare services, this organization also conducts various types of researches.

This organization urgently realized that besides family planning services, if the adolescents could be made conscious in advance about some facts, such as- late marriage, family planning after marriage, formation of small family, maintenance of sound health, etc. these girls may be saved from maternal deaths and child death rate would also decline. With this main objective, FDSR started working with Adolescent Life Education Program at three levels from 1987. These are:
(A) Daughters' Club
(B) Adolescent Girls' Group
(C) Boys' club.

\section{(A) Daughters' Club:}

FDSR started 275 Daughters' club in 4 projects from July 1987. The target group of this organization was girls who were over 13 years of age. At present there are 275 old and 310 new clubs in the 6 projects. The daughters' clubs have currently 4,680 members. This adolescent program is in effect at Raipura, Gopalpur, Modhupur, Godagari, Singra, Satkania and Baskahli. Each club consists of at least 10 members. After a two years

training to the members of a group, the program achieves its maturity and the members of the groups then start to work as voluntary workers.

The main objective of this program is to motivate for late marriage, to prepare the adolescent girls for planned married life in future, to inspire to stand up against the dowry system and to make them conscious about individual rights and responsibilities. FDSR uses its own curriculum for running the daughters' club.

Each of its daughters' club is supervised by a female leader elected by the members of the club. The leader is trained to supervise the activities of the club. The club members hold meeting at a specific place at least once a month under the guidance of the leader, and carry out discussion on various educational topics. 


\section{(B) Adolescent Girls' Group:}

In 1991, FDSR formed 9 adolescent girls groups consisting of unmarried adolescent girls (1216 years old) in suburb based projects (Dhakhinkhan Union of Uttara Thana under

Dhaka district) with the aid of BPHC. At present, there are 16 groups and each group has at least 10-12 members.

The objectives of the Adolescent Girls' Group are to motivate the participants of the program to adopt the following measures:

- To maintain small family size (limited to two children) and motivate others to do so.

- $\quad$ Not to marry before the age of 18.

- Try to take nutritious food, and advise others to do the same.

- Keep the household neat and clean.

- Adopt preventive measures to safe-guard one-self from diseases and advise others to follow.

- Maintain good relation with all the family members.

- Take part in social-welfare activities.

- Prevent environmental pollution.

- Never become dependent financially.

- Become respectable members of the society.

The Adolescent Girls' Group is controlled by a female leader. This group meets in FDSR office once a month. Their health is checked and the results are recorded in a health-card in this office. Saving groups are formed from the adolescent girls group. At present there are 18 saving groups. Each group has 10-12 members. The members make monthly donations (from 0.50 to $10.00 \mathrm{Tk}$.) to the savings account in accordance to their means. Each group has separate bank account. This program is supervised by a paramedic. Regular meetings of the parents and community are held in order to develop consciousness about this program. Besides this discussions are held on women's rights in mosques during Jumma Prayer each Friday.

\section{(C) Boys' Club:}

FDSR formed 17 Boys' Clubs in July 1990, consisting of the unmarried youths (15-25 years old). The organization realized the urgency of family life education for adolescent boys along with adolescent life education for girls which had already been carried out in 4 projects.

Objectives of the Boys' Club

- To encourage late marriage.

- To have babies at mature age and at longer intervals.

- To form small family.

- To create consciousness about duties and responsibilities of society and family.

At present there are 56 boys club in 6 project areas including 17 old and 39 new clubs. Each club has a team leader who is trained for controlling the group. The club holds a meeting once each month under the guidance of the team leader. In the meeting various topics are taught from the organization s self-prepared curriculum. 


\section{Description of Curriculum}

FDSR has prepared two different curricula for adolescent boys and girls. These are discussed below:

\section{Family Life Education Program:}

There are 12 subjects in the family life education curriculum for the rural adolescent girls.

\section{Family:}

Family; structure of family and importance of family; types of family; population problems and solutions; importance of maintaining small family; ways of forming small family; roles of family members and mutual duties and responsibilities towards one another.

\section{Personal health:}

Personal cleanliness; health-care and beauty-care; importance of rest; sleep; labor; eating; indispensability of physical exercise and entertainment; physical and mental changes during puberty; things to be done and avoided during menstruation; mystery behind human birth; knowledge about sterility; child marriage and related discussions; harmful effects of smoking, drinking and drug abuses and ways of overcoming these bad habits.

\section{Neatness and Cleanliness:}

Need for cleanliness and rules for staying clean; clean dwelling place; instructions on family health; measures to be followed in disaster stricken areas after natural calamity; safe water and food; sanitary latrine or toilet.

\section{Diseases:}

Common diseases; causes; symptoms and preventive ways; contagious diseases and prevention; prevention and cure of asthma; high blood pressure; heart diseases; diabetes; goiter; preventive and curative measures of tuberculosis.

\section{Welfare activities:}

Importance of welfare activities; returns of welfare activities; welfare services recipient group; welfare activities in various sectors of the society.

\section{Food and Nutrition:}

Food; elements of food; functions of food and balanced diet; nutrition; malnutrition; causes of malnutrition; diseases caused by malnutrition; intake of food according to age and activities; improved diets at lower cost; daily diet list of an adolescent girl; proper cooking process; qualities and nutritional value of different types of food.

\section{Cooking:}

Need for cooking food; process of cooking; precautions of cooking; various methods of cooking; and preservation of food.

\section{Important Lessons:}

Eating; manners; apparel; few important lessons for becoming good housewife; minor skin problems; hair care; repression of anger; noticeable things at times of purchase of apparels 
footwear; first-aid measures to be followed in case of burns/cuts/falls/entry of alien objects in the ears; liquid mixture of salt and molasses or oral saline; immunization.

\section{Rules and Regulation and Female Education:}

Rules and regulation for women and young girls: rights of women; inheritance; remarriage; divorce and widow-marriage; need for female education; opportunities for female participation in various occupations.

\section{Environment:}

Environment; causes of environmental pollution; population and environment; environmental development and role of plants in preserving the environment; environmental pollution and our responsibilities; pre-conditions of tree plantation; selection of sites for planting trees; sapling nursery; proper ways of planting trees; sapling cares; our socio-economic context and raising saplings.

\section{Memorable days and noble women:}

National and international memorable days.

\section{Self-employment:}

Family vegetable yard; methods of growing nutritious food and poultry farming.

2. Eleven subjects are included in Family Life Education Curriculum for the adolescent boys of the rural areas.

\section{Family:}

Family; formation and structure of family; importance of family; types of family; population problem and solution; need of small family; duties and ways of forming small family; responsibilities of a young man towards his family members; duties and responsibilities towards wife and children; conditions of marriage; family planning in Islam; mystery of human birth and sterility.

\section{Personal health:}

Personal health and cleanliness; role of rest, sleep, labor, eating food, recreation and physical exercise for maintaining sound health; physical and mental changes during puberty; child marriage; causes of child marriage; harmful effects of child marriage; advantages of late marriage; smoking,drinking and abuse of drugs-causes; harmful effects and ways of overcoming these bad habits.

\section{Cleanliness:}

Importance of cleanliness; clean dwelling places; rules of cleanliness and health rules, urgent health measures in disaster stricken areas after natural calamity; safe food and water; sanitary latrine.

\section{Diseases:}

Causes of general diseases; symptoms and prevention ways; contagious diseases and their prevention; causes; symptoms and prevention of various diseases such as-asthma, high blood 
pressure, heart diseases, diabetes, tuberculosis, jaundice, skin cancer; symptoms; causes and prevention of venereal diseases; syphilis and gonorrhea; AIDS; various complication at times of urinating; prevention and cure of gangrene.

\section{Community services:}

Need for community services; returns for service; service recipient clients; ways of providing services in various sectors of the society.

\section{Food and Nutrition:}

Food; elements of food; functions of food; balanced diet; nutrition; malnutrition; causes of malnutrition; diseases caused by malnutrition; food intake according to age and activities; ways of preparing improved diet at lower cost; daily diet list of an adolescent boy; qualities and nutritious value of different food; methods of preserving food.

\section{Important Lessons:}

Manners; apparel; first-aid treatment for cuts/burns/falls/entry of alien objects in eyes or ears; injury to head; heart-attack; life saving measures: in case of snake or animal bites; drowning; dog bites; liquid mixture of salt and molasses or oral saline; immunization.

\section{Rules and Regulation:}

Child marriage preventing laws; female violence preventing laws; laws concerning female rights; dowry prohibition laws; inheritance; divorce; remarriage and widow marriage.

\section{Environment:}

Environment; causes behind environmental pollution; population and environment; environmental development and role of plants in preserving the environment; environmental pollution and our responsibilities; preconditions of tree plantation; selection of sites for planting trees; sapling nursery; proper ways of planting trees; sapling cares; our socioeconomic context and raising saplings.

\section{Memorable Days:}

National Martyr Day; National Independence Day; National Victory Day; Bengali New Year; National Population Day; International Women s Day; International Children s Day; World Environment Day; World Health Day; International Literacy Day; International Peace Day; International Youth Day; International Population Day; International Food Day; International Housing Day.

\section{Self-Employment Projects:}

Family vegetable garden; growing nutritious food; poultry farming and cattle raising; koyl and pigeon raising; pisciculture.

\subsection{Urban Health Extension Project (UHEP)/Urban Volunteer Program (UVP)/International Center for Diarrhoeal Diseases Research, Bangladesh (ICDDR,B).}


Urban Volunteer Program while conducting research at the field level noticed the fact that females and children were the most neglected group in our society. If significant changes can be introduced among the females then this group can play an important role in the society.

UHEP with grants from Ford Foundation started a two year women s empowerment pilot project (WEPP) from June 1990. A number of training programs through experimental

projects were started for women and adolescent girls on various subjects such as- education, law and rights, reproductive health, group savings, investment, income, importance of female education and family planning. Initially 160 girls out of 193 completed the program successfully. The program attracted wide attention in the slum areas. Presently the program is not being implemented due to lack of funds.

\section{Description of Curriculum}

Naripakha was given the responsibility to prepare a curriculum on reproductive health. The curriculum was titled My Body, my decision . This contains discussion on 11 topics, such as reproductive health and rights : Whether the new born will be male or female, why females are female and why males are male, sex determination; $\mathrm{XX}$ for a boy and $\mathrm{XY}$ for a girl.

\section{Puberty:}

(a) Discussion on external physical changes of boys and girls of 9-10 years. Influence of hormone in inducing these changes. Some hormones produced in brains are circulated through the body which causes these changes.

(b) hymen-hymen is a thin membrane between vaginal tube and uterus; types and descriptions of hymen;

(c) breast development; stages of breast development; pubic hair; external sexual organs; illustrated description of internal sex organs;

(d) reasons for menstruation and influence of hormone on menustration; condition of body during menstruation; neatness and cleanliness; and illustration of menstruation cycle through six diagrams.

\section{Male changes:}

(a) Penis-physical description (with illustrations) of penis before and after circumcision;

(b) description of penis growth and testicles;

(c) pregnancy-description of germination of ovule and spermatozoid.

\section{Birth control:}

(a) safe-period; withdrawal; condom (for male);

(b) foam tablet (for female);

(c) copper-T (IUD);

(d) hormonal methods- two types of injections: depo-provera (3 months), norestrate (2 months); NORPLANT (birth spacing for about five years); effectiveness and sideeffects of hormonal methods;

(e) oral pills (currently the most popularly used method); details on various topics such as ways of taking pills; instructions for using pills; measures to be followed if one 
forgets to take pills one or two days in a row; physical check-up at least once a year, etc.;

(f) menstruation regulation (abortion);

(g) vasectomy;

(h) ligation.

The use of these family planning methods, their effectiveness and side-effects are represented elaborately in chart form. The methods for male and female are described separately.

\section{Pregnancy:}

(a) symptoms of pregnancy

(b) taking care of the pregnant women

(c) breast feeding

(d) sterility.

\section{Menopause:}

Mental and physical changes during this period and solutions.

\section{Sexuality:}

Indispensable part of human life; sexual needs are considered as normal by the scientists. However, it is disrespectful and illegal to force someone for this purpose.

\section{STDs:}

Sexually transmitted diseases such as, gonorrhoea, syphilis, harpies, AIDS. Use of condoms to protect from sexually transmitted diseases.

\section{Individual care:}

(a) check regularity of menstruation;

(b) take uneasiness or pain seriously;

(c) drink enough water and not suppress urine when in pressure.

(d) check breasts once a month for tumors (illustrated description).

\subsection{Under Privileged Children's Education Program (UCEP), Bangladesh}

This voluntary organization started a community school project on experimental basis in 1973 in the slum areas of the city comprising of boys and girls dropped-out from school or deprived of schooling due to poverty. In later periods, UCEP started non-formal education with the objective to improve the condition of poor boys and girls not enrolled

in school or dropped-out from school. The standard of the non-formal education offered by UCEP is equivalent to class seven of the formal schooling system. Later on, these students may take part in the technical training provided by UCEP. According to the statistics of 1994, UCEP currently has 26 schools. The present number of students is 12,000 and $50 \%$ of the students are girls.

\section{Description of curriculum}


UCEP follows self-prepared curriculum for primary education program. The title of this curriculum is Health, Society and Science. It is divided in two parts, one is for the teachers and the other is for the students (from class 1 to class 5).

The curriculum is as follows:

1. Teachers Guide: Health, Society and Science- Class One

(a) family and family environment;

(b) rules and regulations;

(c) food;

(d) water,

(e) first-aid treatment;

(f) tales of the country.

2. Teachers Guide: Health and Social Science- Class Two

(a) environment and personal environment;

(b) food and health;

(c) prevention and treatment of diseases;

(d) security;

(e) child rights;

(f) direction, time and clocks.

3. Teachers Guide: Health, Society and Science- Class One, Two and Three, General idea;

(a) social environment: family, society and occupation;

(b) personal area and local environment;

(c) child rights;

(d) earth, solar system and universe;

(e) water;

(f) balanced diet. 
4. Health, society and Science - Class One

(a) Family and family environment

General idea; small family and large family; advantages of small family; own name and age; parents' name, position and address of own residence; self-occupation and parents' occupation; manners of the students within family environment; role of father, mother, brothers and sisters in the family.

(b) Rules and Regulations

General idea; rules and regulations of school; manners of school students.

(c) Health and cleanliness

General idea; ways and importance of keeping body, cloth, house and school clean; harmful effects of staying dirty.

(d) Diet

Concept; family diet; nutritious food; nutritious food at lower cost; concept of stale and contaminated food; harmful effects of taking stale (not fresh) food; methods of food preservation; preparation for consuming food.

(e) Water

Sources of water; concept of safe water and contaminated water; how to obtain safe water; harmful effects of using contaminated water.

(f) First-aid

Concept; measures to be taken during common illnesses such as- fever, cold, cough, cut or burn, etc.

(g) The Country

Concept; our country; national anthem; national symbol; national flag.

5. Health, Society and Science- Class Two

(a) Environment and personal environment:

Concept and example; importance of keeping environment clean; harmful effects of polluted environment; ways of keeping the environment clean; responsibilities of the students in keeping the environment clean.

(b) Diet and Health

Concept; need for food; different types of food and their functions; idea about energy producing, growth inducing, compensating and disease preventing food; importance of sound health; ways of maintaining sound health.

(c) Treatments and Prevention of Diseases

Concept; name of some common diseases; causes of common diseases; ways of preventing diseases; organizations engaged in disease prevention and treatment (areabased).

(d) Security 
Concept; what is social security; what is accident; causes of accident; precautions against accidents; organizations engaged in security services (government security systems)

(e) Child rights

Concept; five child rights: 1) food; 2) home; 3) health; 4) education; 5) security.

(f) Direction, time and clocks

Concept; ten directions; days; week; month; year, era, century; create familiarity with clocks or watches.

\section{Health, Society and Science: Class Three}

(a) Social environment- family, society and occupation.

Concept; types of family; advantages of small family; how societies are formed; various occupations of society; our responsibilities as members of the society.

(b) Personal area and local environment

Concept; structure and functions of local organizations such as- neighborhood, ward, thana, municipality, and district.

(c) Child rights

Concept; some child rights:-1) food; 2) health; 3) education; 4) entertainment and playing facilities; 5) safety rights against commercial and sexual exploitation; 6) rights to avoid participation in war or other combats/fights; 7) safety rights against physical and mental abuse.

(d) World and Universe

Concept; area, shape, location and features of earth; area, shape, location and features of the sun; concept of day and night; shape, area, location and feature of the planets; area, shape, location and features of the moon.

(e) Water

Sources of water; concept of safe and contaminated water; how to purify water; harmful effects of using contaminated water; diseases caused by contaminated water.

(f) Balanced Diet

Concept; types of food; energy and calorie producing food-concept and examples; body building and growth inducing food-concept and examples; disease preventing food- concept and examples; balanced diet at lower cost; methods for preserving foods. 


\section{Health, Society and Science- Class 4}

(a) Nature, Environment and Life-style

Concept; environmental changes and its influences on human; changes in environment; influence on flora and fauna; reasons for rapid environmental pollution in slum areas; our responsibilities in preserving the environment.

(b) Population

Concept; population growth; example; disadvantages of population growth; disadvantages of increase in the number of family members; influence of population growth on food, house, school, transportation system.

(c) Students' role in maintaining family health

Concept; preventive measures-health promoting activities for all family members; preventive measures; treatment measures.

(d) Names, particulars and programs of organizations engaged in health promoting activities (area-based).

(e) names of social welfare organizations; their programs and usefulness (area-based).

(f) Names and introduction to different religions; their essence.

(g) Introduction to games; physical exercises; music; debates; speech; recitation of poems.

(h) Self-employment-examples (Job oriented).

8. Health, Society and Science- Class 5

(a) Bangladesh- our country Independent state; national flag; national anthem; national symbol; national bird; national flower; national fruit; area; geographical location; and population; inhabitants and nationality; language; administration and justice.

(b) Emergence of Bangladesh

Language movement- reasons and outcomes; names of the martyrs; reasons behind the war of independence and outcomes; names of the freedom fighters awarded Bir Sresta title.

(c) Communication

Postal; telegraph; telephone; radio; television; satellite; cinema and news paper.

(d) Matters and Energy

Concept; heat- sources of heat and uses; sound-sources of sound and uses; electricitysources and uses; light- sources and uses. 
(e) General Diseases and Prevention

Diarrhoea- symptoms and cure; instruction on preparation and use of oral saline; dysentery- symptoms and prevention; measles and small pox- symptoms and cures; diphtheria; polio and tetanus-symptoms and cure; skin diseases and its cures; night blindness- symptoms and cures; ways of preventing these diseases.

(f) World Children s Day

Concept and significance; child rights- concept and child rights; name of the organizations engaged in various child welfare activities.-UCEP, World Vision, Terres Des the Homes, Raddabarnen, Shaishab, Gano Shahajja Sangstha and Ahsania Mission.

\subsection{Center for Mass Education In Science (CMES)}

CMES offers lessons through non-formal primary education on topics such as, general education, technological training and its economic application, health and environment, etc. Along with these, it started adolescent girls' program from 1991. At present, the adolescent girls' program comprises elementary school girls' and ex-elementary school girls. Each unit comprises female students aged between 11 to 19 years. About 200 members are included in one unit. These members are divided into a number of groups among the technological centers of the different elementary schools. There are 5 females in each group. Teachers of the adolescent girls' program and their assistants maintain one class on adolescent girls program per week. Classes are held on week days for those girls who study in secondary schools.

Half of the adolescent girls of the unit take part-take in meeting each month. Adolescent meetings are held regularly at fifteen days interval. Workshops for mother and adolescent girls are held twice a year. The fathers are also invited to attend this workshop. Adolescent girls' program is carried out in 22 areas- Suruj, Tangail, Kayetpara, Gazipur, Shakhipur, Kuriapara, Sirajganj, Dewti, Rangpur, Raniboroddhor, Dinajpur, Satbaria, Chittgong, Kasherhat, Patuakhali, Amua, Jhalokathi, Amtole, Barguana, Pathargata, Bhatpara and Rajshahi.

\section{Objectives of the adolescent program}

- To ensure normal preparation period for every adolescent girl as well as the opportunity to grow up jovially.

- To emancipate the adolescent girls from all discriminations, restrictions imposed during puberty, and hostile superstitions.

- To continue education, technological training, and practice sessions.

- To provide knowledge and develop consciousness, about adolescent girls health, their reproductive health, their rights, and to uphold these rights. 
- To familiarize on Basic rights, create consciousness about family and social rights, standing up for establishing the rights. To invigorate the boys to perform equal duties simultaneously towards society and family.

- To inculcate Individuality of the adolescent girls and cultural development.

- To adopt income generating programs for financial self-support and taking loans in need and productive use of loans.

- To prevent child marriages, discourage marriage of adolescent girls before acquiring adequate education, practical experiences, and becoming self-sufficient. Motivate the adolescent girls not to marry before the age of eighteen.

\section{Description of Curriculum}

The description of adolescent girls' curriculum is provided below:

(a) Teachers' guide on adolescent girls' program - Science mass education center.

1. General education.

2. Technological training and practice.

3. Health and Nutrition- Lessons on health; determination of nutrition; diagnosis of general diseases and first-aid treatment.

4. Reproductive health- what is reproductive health; development of reproductive health; reasons behind impairment of reproductive health:

(a) due to ignorance;

(b) due to attitude;

(c) due to birth restriction measures;

(d) due to poverty;

(e) ensuring reproductive health through empowerment of women;

(f) changes during puberty and adolescence;

(g) what is menstruation;

(h) precautions during menstruation;

(i) what is pregnancy and roles played by male and female in conception;

(j) risks of pregnancy at early age;

(k) family planning;

(l) oral pills;

(m) rhythm;

(n) condoms;

(o) coil.

5. Rights of the adolescents and implementation of the rights.
(a) human rights;
(b) social rights;
(c) legal rights; 
(d) consciousness about women rights;

(e) divorce by the husband;

(f) denmohor;

(g) maintenance;

(h) regaining conjugal rights;

(i) guardianship of minor children;

(j) rights to enjoy property;

(k) divorce rights of wife;

(l) second marriage;

(m) marriage prior to becoming adult.

6. Family life of women

(a) Family life and role of women in formation of family (current state);

(b) parents family;

(c) husbands family;

(d) appropriate role of women in the family;

(e) household chores-women the sole worker.

7. Financial self-sufficiency of women

(a) Technological skill and commercial dexterity;

(b) market demand.

8. Credit facilities of adolescent girls program

(a) target group;

(b) objectives of adolescent girls-credit program.

9. Social work and preservation of the environment

(a) role of the adolescent girls in preserving environment.

10. Personality and cultural development

(a) conversation;

(b) movement;

(c) behavior;

(d) taste;

(e) enthusiasm and courage;

(f) agility and persevering attitude;

(g) flourish cultural and sports potentialities.

11. Slogan of the adolescent girls' program

(a) 'Aye Chelera Aye Meyra'- an elementary school level book for adolescents on equality of male and female.

Expectations of Ferdousi; what will you be; expectations of a nice home; football; attempts to fulfill expectations; every one should get a chance; sister Mahfuza; girls are not weak; behave equally well with others when one becomes famous; woes of Alim; be watchful from now on; your adolescence; some of them; importance of adolescence; Asiea's mother; place 
of women in family; rearing child is not the sole task of women; stories on uprising of the women; Sokhina's flute; ways of establishing rights.

\subsection{Bangladesh Rural Advancement Committee (BRAC)}

BRAC started the program of primary education in 1985 along with its other development programs. In 1994, the number of school under the project was 28,000 . In primary education the students are taught the following subjects program- Bengali, maths, introduction to environment, and lessons on health. At present, BRAC has two types of model schools.

1. Non-Formal Primary Education ( NFPE) - 3 years' school program: Age limit of the students is 8 to 10 (those who were never enrolled in school or have dropped-out from school from class one).

2. From 1988, a three year course titled - 'Basic Education for Older Children (BEOC)', has been started through BRAC for those boys and girls who were never enrolled in school and fell in the age group of 11 to 14 years. This school model is also known as adolescents school. Under this program, adolescent schools have been set up in health and population program areas. The students are taught by female teachers in these schools. These schools put special emphasis on health education for the adolescents of 11 to 14 years. Under this course system, health education is imported together with other lessons from class II. Each girl is supplied a health card in which she records her height, weight and diseases. Humanitarian concepts along with social codes of manners and values are also included in these lessons. The community as a whole, including the teachers, students and their parents, is engaged in maintenance of these part-time education centers.

At present, there are 830 adolescent schools in various health population program areas. In 1994, 191 schools have completed their three years course. Rural Development Program (RDV) maintains another 30 schools.

\section{Objectives of the program}

To teach lessons on general health and reproductive health besides primary education.

To make the adolescents conscious about their general health and reproductive health so that they may grow up into healthy mothers and take good care of their children. 


\section{Description of the curriculum}

Besides their different curricula BRAC uses the following books for implementing their project- Our health 2 nd part for providing education on health, and introduction to society 1st, 2nd, and 3rd part for providing education on one-self, family and diseases. The books are prepared in congruence with the daily life, and the students can easily apply their knowledge and ideas in their practical lives. Various discussions on health, family and environment are presented with attractive illustration in simple language in these books.

The subjects on which health education is provided besides primary education are discussed below.

'Our Health'-Part Two: Contains illustrated description of various physical changes of males and females from childhood to adulthood.

\section{How Do We Grow Up}

(a) Various physical changes from childhood to adulthood;

(b) nutritious food;

(c) education;

(d) mixing with people.

\section{Menstruation}

(a) Physical cares during menstruation;

(b) nutritious food and all types of food;

(c) cleanliness.

\section{Mother care}

Frequent child births are detrimental to both maternal and child health; changes observed in pregnant woman- shown through illustrations in stages; after- 2 months, 4 months, 6 months, 9 months etc;

(a) diet of pregnant woman;

(b) how to recognize anemia;

(c) bad-effects of early marriage.

\section{Child-care}

(a) Illustrated description of the tools such as blade, sterilized string, etc, essential for healthy and safe delivery;

(b) child cares: feeding them with care, playing with them; speaking with them in distinctpronunciation; making toys for them.

\section{Three diseases caused by malnutrition}

(a) how to recognize marasmus and measures to be adopted;

(b) how to recognize kwashiorkor and measures to be followed;

(c) night blindness;

(d) the children requiring special attention - the children who can not see, can not speak, can not walk; how to be friends with these children, playing with them and making them happy. 


\section{Diseases:}

(a) attacks of fevers; how germs enter the body, like- using or drinking contaminated water; taking food with dirty hands; consuming stale (unfresh) food; roaming in bare feet; staying unclean; living in unhealthy environment;

(b) some diseases: symptoms of pneumonia and measures to be followed, symptoms of TB and measures to be followed.

\section{Family Care:}

(a) Disadvantages of having too many family members;

(b) definition of happy family; consulting with health workers and doctors for keeping the family size small;

(c) consulting centers; family welfare centers; hospitals; upazilla health complexes; mother-care centers.

\section{Introduction to Environment- 1st, 2nd and 3rd part}

\section{Introduction to Environment- 1st part}

(a) Information about self: Learning own name and name of other students; self appearance; height; various organs of the body; age; names and need of various types of dresses; ways of keeping dresses clean;

(b) our family: how family is formed; number of family members; role played by father and mother in the family; relationship between brothers and sisters; helping the elderly persons in the family; responsibilities towards infants and children of the family;

(c) our households; need for houses; own room; functions of different rooms of the house; need for separate toilet facilities and maintaining them;

(d) our neighbors: who are neighbors; benefits of friendly relations with the neighbors;

(e) possible inconvenience due to disagreements;

(f) food: names of 10 food items; needs for food; sources of food; foods obtained from plants and animals;

(g) rules for consuming food: mealtimes; need for timely meals; stale (not fresh) food; harmful effects of stale (not fresh) food; how food becomes polluted; use of water; safe drinking water; contaminated water; causes of water pollution;

(h) pets: keeping pet animals and birds; know the names of pet animals and birds and take care of them; keep their places clean and know about pet-foods;

(i) direction, days and time: learning the names;

(j) cleanliness: differences between a clean and dirty person; difference between healthy and dirty environment; advantages of staying neat and clean; know the methods of keeping hands, feet, nails, hair, ears, skin, mouth, nose and teeth clean; know the methods of keeping dresses, beds and houses clean;

(k) accidents and precautions against accidents: water, fire, sharp instruments, vehicles, insecticides, falling from high places or trees;

(l) our village;

(m) our country: Bengali language; national flower, national bird, national fruit, national fish, national animal, and national flag and national anthem. 


\section{Introduction to Environment- 2nd part}

The following topics are discussed with illustrations:

(a) Family: Mala s family; works performed by father and mother; Siblings; relationship between brothers and sisters; domicile;

(b) social environment: family; neighbors; social harmony; social works; observing social festivals; helping others;

(c) our households: house; bedroom; kitchen; cow-shed; latrine; poultry; ponds; water taps;

(d) food: sources of food; reasons for taking food; functions of food; polluted food; keeping food healthy; preserving food; preventing wastage of food; amount of food;

(e) body and health: hands; feet; teeth; eyes; nose; ears and hair; reasons for preserving good health illness; liquid mixture of salt and molasses; whooping cough; measles; tetanus; TB; polio; diphtheria; health and seasons;

(f) pet animals and birds: cow; goat; duck; hen; pigeon;

(g) organizations; offices and transports: mosque; maktab (religious education center); madrassa (religious education center); hospitals; police stations; clubs; post offices; animal husbandry offices;

(h) natural environment: earth; water; air; plants;

(i) crops;

(j) our country: map of Bangladesh; main cities; rivers; forests; national flower; national fruit; national animal; national fish; national flag and national anthem.

\section{Introduction to Environment - 3rd part}

(a) Food: growth inducing and compensating food; energy producing food; diseases preventing food;

(b) first-aid treatments; minor or major cuts; what to do in sudden cases of fainting/burns/entry of alien objects in the eyes;

(c) diseases: few diseases- diarrhoea; night blindness; anemia; few contiguous diseasesjaundice; skin diseases; chicken pox; fever; common cold; eye infection; intestinal worms; preventive vaccination;

(d) ways of additional work: growing vegetables; poultry farming; raising cattle; cottage industry; petty business;

(e) works of the society: misunderstandings; social works; groups; associations;

(f) our well-being: dowry; spells and talisman; harmful effects of these things;

(g) Bangladesh and population;

(h) natural environment: earth; water; plants; living beings;

(I) our country: geographical location; map of Bangladesh; earth; river; agriculture; forests; mines; factories; national flag;

(j) universe; moon; solar system.

\subsection{Dhaka Ahsania Mission (DAM)}

DAM is an old voluntary organization. Along with other social welfare programs it is working with practical education program for different age groups through non-formal education. In the beginning, adolescent life education program was incorporated into adult 
practical education. The age limit was then fixed at 11-45 years and health education was also provided through adult education. It was observed in the classes that the adults and the adolescents could not be taught in the same class due to considerable difference in age between these two groups. Under this circumstances the management committee decided to take separate classes for the adolescents.

\section{Objectives of adolescent life education}

- To teach the adolescents through non-formal education and make them self-sufficient by providing training on income generating projects.

- To grow consciousness among them.

- To build up the confidence among the adolescents to take responsibilities as an efficient member of the family as well as to take care of the parents in future.

The age limit of the adolescents has been fixed at 11-17 years. At present, the total number of groups is 295 . There are 25 members in each group. Among the total of 8450 members, $60 \%$ are adolescent girls and $40 \%$ are adolescent boys. The adolescent life education program is continuing in various areas such as, Norshingdi, Jhenidah, Jessore, Satkira and at Amtali of Borguna. The project is implemented at the field level in these areas. There is a teacher (male/female) for each group. These teachers are trained for practical education program.

\section{Description of Curriculum}

With representatives from 16 organizations Dhaka Ahsania Mission in a workshop held in 1992 prepared a curriculum on adolescent life education by including 5 practical subjects. These are:
(a) family and society;
(b) health and environment;
(c) income and values;
(d) behavior and values;
(e) country, culture and rights. 
The curriculum is described below.

Adolescence Study- 1st and 2nd part

The 1st and 2nd part contain elements of learning Bengali and mathematics. The figures used for illustration are mostly based on social consciousness.

Adolescence Study- 3rd part

This part contains social lessons, as well as lessons relating to rules and regulations, cleanliness etc. For example-

(a) justice (Jarina's Child, letter on women trafficking);

(b) staying away from diseases;

(c) treatment of diarrhoea;

(d) cottage industry;

(e) poultry farming;

(f) our society;

(g) standing up against injustice;

(h) child marriage; marriage laws;

(i) relationship with neighbors; live in harmony;

(j) usefulness of plants; pure air;

(k) modern hearth;

(l) cultivation;

(m) staying away from superstitions;

(n) treatment of jaundice;

(o) basic rights;

(p) receiving legitimate wage;

(q) working in groups for the people and development of the country;

(r) games and physical exercises;

(s) project building;

(t) our society; social welfare;

(u) war of independence of Bangladesh.

\subsection{World Vision (WV), Bangladesh}

The adolescent life education program was started through Child Sponsorship program. This organization started AFLE program in 8 project areas from January 1992 through Family Health Education Program . WV is continuing with this program for the old adolescent girls of aged 9-18 years with the help of 160 trained persons as mass development workers and health workers.

At present, adolescent life education program is being continued in 200 projects of different districts, such as- Dhaka, Gazipur, Manikganj, Narayanganj, Netrokona, Jamalpur, Sherpur, Sripur, Comilla, Chittagong, Bandarban, Cox s Bazar, Barishal, Bagherhat, Khulna, Sathkira, 
Bogura, Faridpur, Madaripur, Rangpur, Jaipurhat, Sirajganj, Natore, Pabna, Jessore and Meherpur.

Child Sponsorship program encompasses 68,000 boys and girls from school to university level. While running this program WV observed that the girls were not provided adequate meals as compared to the boys. Due to acute negligence on the part of their family full physical development does not occur for these girls and they become victims of various types of diseases. For this purpose, WV realized the urgency and importance of this program. As a result, 80 adolescent girls from Child Sponsorship Program were included in adolescent life education program.

The main objectives of the adolescent life program are:

- To help the adolescent girls in building up a happy and self-sufficient life by providing them education, health education, and development training.

- To ensure that a girl gets equal amount of food in the family. Every body in the family should pay equal importance to them and fulfill his/her responsibilities towards them.

- To develop consciousness and principles about their role in the society and family.

- To develop social consciousness (dowry, child marriage, rights).

In this program, the girls are divided into two groups: (a) 8-12 years age group and (b) 12-18 years age-group. In the first group, health lessons are usually taught along with formal education. In the second group, various income generating trainings are provided along with formal education and health lessons.

One class is held each week for the adolescent girls. Each group has 20 adolescent girls on average. The class is taken by the field workers of the project. Usually public health nurse, paramedic, and doctors help in taking classes on the curriculum. At present, the students are taught about primary health by the school teachers.

The adolescent girls excluded from the Sponsorship Program but interested to join the adolescent life education program are encouraged to participate. WV is considering to start a similar program for the boys also.

\section{Description of the Curriculum}

WV has its own curriculum for adolescent life education program. Some additional subjects are also taught, such as- reproductive health, STDs, syphilis, gonorrhea, etc, and for this purpose curriculum prepared by VHSS or other organizations are used.

Family health education for adolescent girls- training manual, World Vision of Bangladesh.

Instruction for taking session on family health education: 
Preparation; go through the instruction guide thoroughly; two stages of study plan; rehearsal before session; orientation; main session; topic; objective of study; introduction; main discussion; summary; evaluation; valedictory part.

\section{Lesson no-1:}

Honor and Dignity of Women

Introduction; urgency to develop honor and dignity; ways of augmenting honor and dignity of women; education; health and self-sufficiency; enhancing co-operation and efficiency; obstacles for the females in earning respect and ways to overcome them.

Lesson no-2:

Food and nutrition

Introduction; nutrition; balanced diet; protein; carbohydrate; fat; vitamin; vitamin-A; vitaminB; vitamin-C; mineral salts; iron; calcium; iodine; summary.

\section{Lesson no-3:}

Breast milk for children:

Introduction; advice; breast feeding new babies immediately after birth; frequent breast feeding increases breast milk; breast milk is sufficient for fulfilling the nutritional needs for the baby upto four months; breast milk is best and safest for the baby; bottled milk may cause various diseases even deaths to babies; feeding breast milk to babies upto two years and further if possible; advantages of breast milk; how to continue breast feeding for long; summary.

\section{Lesson no-4:}

Blindness due to malnutrition

Introduction; severity of blindness from malnutrition; food rich in vitamin-A; preventive ways of night blindness; baby food; intestinal worms; vaccination; diarrhoea; high powered vitamin A capsule; summary.

\section{Lesson no-5:}

Nutrition of the adolescent girls

Introduction; requirement of nutritious elements; protein; mineral salt; higher nutrition at lower cost; summary.

\section{Lesson no-6:}

\section{Dowry}

What is dowry; punishment for dowry; reasons for dowry; social customs and superstitions; inheritance law; competition of the rich; lack of education; lack of self-respect; economical weakness; lack of earning scope for the women; urgency for abolishing dowry systemeducating the girls; earning capacity of the females; widespread hatred of the society against dowry; wide publicity of laws prohibiting dowry and arrangements for quick trials. 


\section{Lesson no-7:}

Child marriage and health

Definition of marriage; conditions of marriage; age; consent; denmohor; registration. Reasons behind child marriage: relief from responsibilities; menstruation for the first time; new relations; fanciful desires; lack of scope of education; social custom; ignorance of laws; lack of education; and superstitions. Effects of child marriage on health: high maternal death rate; obstruction in proper physical development of females and other complexities; negative attitude towards sexual intercourse; failure in rearing new born babies; underweight new born babies; high rates of pregnancy. Abolishing child marriage system: create consciousness about child marriage preventing laws; increase literacy rate among the girls; raise consciousness about child marriage prohibition law; poverty alleviation; summary.

\section{Lesson no-8 :}

Mental health

Mental health in adolescence- relation between mental and physical health, impediments to soundness of mental health; lack of educational environment despite interest; negligence of the guardians; marriage of adolescent girls by guardians inspite of their disapproval; likingslaffection and impediments due to family reasons. How to keep mental health soundindividual discipline; family discipline; religious values; Know about the greatness of the universe; reading biographical essay of the celebrities; refraining from tension and anxiety; balanced diet and proper physical exercise; summary.

\section{Lesson no-9:}

Immunization

What is immunization; advantages of vaccination; diseases prevented by vaccination; who are to be immunized; time for immunization; possible problems of immunizations; summary.

\section{Lesson no-10:}

\section{Diarrhoea}

What is diarrhoea; reasons behind diarrhoea; why diarrhoea is dangerous; how diarrhoea creates water shortage in the body; three methods for treatment against diarrhoea-feed a child more water than usual requirement; prepare oral saline or liquid mixture of salt and molasses in home, summary.

Lesson no-11:

Iodine deficiency related problems

What causes goiters; social problems of goiter; problems in Bangladesh due to iodine deficiency; sources of iodine; cure and prevention; preserving the qualities of iodized salt, summary.

Lesson no-12: 
Personal Cleanliness and Healthy habits

Personal cleanliness; urgency of personal cleanliness; ways of staying clean personally; effect on health; baths; taking care of hands and nails; teeth and hair; apparel; feet; skin. Healthy habits; rest; sleep; labor; eating food and entertainment; summary. 
Lesson no-13:

Intestinal worms

Reasons behind growth of worms; effects on health types of worms; ways of preventing worms; detecting existence of worms; measures to be taken; summary.

Lesson no-14:

Environment and health

Plants for promoting environment; housing for promoting environment; garbage disposal and environmental development; human waste disposal and environmental development; summary.

\subsection{Concerned Women for Family Planning (CWFP)}

This organization started adolescent life education program along with family planning services from 1991 with the financial assistance of BPHC. This program was initiated in two areas-Rajshahi and Bhoirab in Shibpur. The adolescent girls aged between 13 to 15 years are included in this program. Classes on adolescent life education are taken through non-formal groups. Each group has 15 to 20 girls. At present there are 17 groups, among these 14 groups are in Rajshahi and 3 groups are in Bhoirab.

The principal objective of this program is to provide information on female health and make the adolescents self-conscious through adolescent life education program.

\section{Description of Curriculum}

CWFP has no self prepared curriculum for this program, it uses the curricula prepared by VHSS and BPHC. The curricula are discussed below:

Physical and mental changes of male and female during puberty; what is puberty and when it starts; related changes and importance.

Importance of nutritious foods during puberty; mystery of birth; male and female reproductive system; what is menstruation and how it happens; menstruation cycle; role of mother and father in sex determination of the new born.

Sexually transmitted diseases- what are sexually transmitted diseases; types and description of these diseases; prevention; discussion.

What is population education; family planning and need of family planning; responsibilities of parents; responsibilities of the children towards their parents; reasons for the responsibilities; things done by the parents for their offspring.

Values of the adolescents; formation of character; what are values; guiding issues for formation of values; necessary steps for character building.

Friendly relationship between boys and girls; mutual dependency; existing relationship between boys and girls in our country; need for friendly relationship between boys and 
girls; how to preserve this friendship; what is mutual dependence; why it is important and how to maintain it; discrimination in behavior towards boys and girls; mental and emotional problems of the boys and girls; review.

Urgency for training the adolescents; rules and techniques for forming groups with the adolescents.

Strategies for providing training; difference in teaching and training; learning rules for the adults; methods of training.

Preparing training curriculum; exercise of preparing curriculum; review.

Honor and dignity of women; dowry; child marriage; female oppression.

The discussion on the programs of 11 different organizations reveals that (a) the main program of each organization is different, (b) the curriculum on adolescent life education was prepared in accordance with the requirements of the program, (c) each organization has selected topics of the curriculum in congruence with their main program. As a result, it was observed that even though the main subjects of the curriculum were the same the topics discussed within the subjects were different. Different organizations have discussed different topics in accordance with their project requirements. 


\section{Chapter Four}

\section{ADOLESCENT LIFE EDUCATION CURRICULUM USED BY DIFFERENT VOLUNTARY ORGANIZATIONS}

\subsection{Introduction}

In the previous chapters we have described the programs and curricula of 11 organizations on Adolescent Family Life Education. In this chapter we will look into the subjects emphasized by different organizations in their respective curricula.

The discussion on different programs in the previous chapter discloses that a uniform Adolescent Family Life Education has never been effective in Bangladesh. Every organization through its own programs like primary education, family planning, maternal and child health, income generating project, family development etc. started adolescent life education programs. For this reason even though their main topics of the curricula are the same but the topics included in the curriculum are different.

The evaluation of the AFLE curriculum of different organizations suggests that the present program is based on seventeen topics. Among these topics some common topics have been addressed by all the organizations. The priority issues are serially listed below in accordance to the evaluation report. 
Table 4

Main Topics of Curricula and Name of Organizations

\begin{tabular}{|c|c|c|c|}
\hline \multicolumn{2}{|c|}{ Topic } & \multirow{2}{*}{$\begin{array}{c}\begin{array}{l}\text { Number of } \\
\text { Organization }\end{array} \\
9\end{array}$} & \multirow{2}{*}{$\begin{array}{l}\text { Name of Organization } \\
\text { FPAB, FDSR, CDS, World Vision, FPSTC, } \\
\text { Ahsania Mission, CMES, UCEP-Bangladesh, } \\
\text { BRAC. }\end{array}$} \\
\hline 1. & $\begin{array}{l}\text { Social Laws, Rights and } \\
\text { Values. }\end{array}$ & & \\
\hline 2. & General Health & 9 & $\begin{array}{l}\text { FPAB, FDSR, FPSTC, CDS, World Vision, } \\
\text { BRAC, CMES, UCEP, Ahsania Mission. }\end{array}$ \\
\hline 3. & Food and Nutrition & 8 & $\begin{array}{l}\text { CDS, FPSTC, World Vision, BRAC, UCEP, } \\
\text { FDSR, FPAB, CMES. }\end{array}$ \\
\hline 4. & $\begin{array}{l}\text { Reproductive Health } \\
\text { Education }\end{array}$ & 8 & $\begin{array}{l}\text { UHEP, ICDDR,B; CDS, FPAB, FPSTC, FDSR, } \\
\text { CMES, BRAC. }\end{array}$ \\
\hline 5. & $\begin{array}{l}\text { Family Life and } \\
\text { Environment }\end{array}$ & 6 & FPAB, FDSR, BRAC, CDS, UCEP, CMES. \\
\hline 6. & $\begin{array}{l}\text { Female Education/ Rules } \\
\text { and Regulation }\end{array}$ & 5 & FDRS, World Vision, FPSTC, CMES, CDS. \\
\hline 7. & Population Education & 5 & FPAB, FPSTC, CDS, FDSR, UCEP. \\
\hline 8. & Family Planning & 6 & $\begin{array}{l}\text { FPSTC, FPAB, CDS, UHEP, ICDDDR, B; } \\
\text { CMES. }\end{array}$ \\
\hline 9. & Primary Education & 3 & BRAC, FPAB, Ahsania Mission. \\
\hline 10. & Health and Environment & 3 & BRAC, World Vision, FDSR. \\
\hline 11. & $\begin{array}{l}\text { Self-Employment and } \\
\text { Income Generating Project }\end{array}$ & 3 & CMES, FDSR, Ahsania Mission. \\
\hline 12. & $\begin{array}{l}\text { Women's Financial Self- } \\
\text { Reliance. }\end{array}$ & 1 & CMES. \\
\hline 13. & Mental Health & 1 & World Vision. \\
\hline 14. & Child Right & 1 & UCEP \\
\hline 15. & Subjects for Learning & 1 & FDSR \\
\hline 16. & $\begin{array}{l}\text { Personality and Cultural } \\
\text { Development }\end{array}$ & 1 & CMES \\
\hline 17. & $\begin{array}{l}\text { Female-Male Disparity in } \\
\text { patriarchal society. }\end{array}$ & 1 & CMES \\
\hline
\end{tabular}


Seventeen issues have been shown in Table-4. The number and name of the organizations who have incorporated these issues in their curricula are provided in the Table (4) above.

The next tables show more clearly the topics discussed under each subject incorporated in the curricula.

In the evaluation it is noticed that ninety percent of the organizations have given top priority to three main issues in their programs. These are:

(1) social laws, rights and values;

(2) general health; and

(3) food and nutrition.

The main seventeen issues of the curricula are discussed below under separate headings.

\subsection{Social Laws, Rights and Values}

This specific topic has been given the highest emphasis in the AFLE programs. Various aspects of this topic have been considered. Most of the organizations focused on dowry and child marriage issues in details to build up social consciousness against these two harmful practices in the society.

Within this category, FPAB focused on several issues. These are: social values and faith; their effects on individual family and state; religion and its importance in social and family life; cultural change and social problems accompanying modernization and social laws and rights. In addition, CDS, FDSR and CMES have provided explanation of the following topics in their curricula:

Child Marriage Prohibition Act

Divorce Law

Muslim Marriage and Divorce Law

Denmohar and maintenance expenses

Female Violence Prevention Act

Dowry Prohibition Act and

Inheritance Law

Every organization involved in the AFLE program discussed more or less about dowry but World Vision addressed this issue more extensively in its curriculum. It covered all aspects of it, such as- what is dowry, reasons for taking dowry, 4 ways of eliminating dowry system etc. in its curriculum.

The child marriage issue has been incorporated in the curricula of almost all the organizations while this topic has been most pellucidly addressed in the curricula of three organizations, namely World Vision, FPSTC and CMES. 


\subsection{General Health Education}

The FPAB curriculum provides the most informative analysis of this topic. Moreover, CDS and FPAB give exhaustive accounts of eight elements of primary health education.

Ninety percent of the evaluated curricula discussed the following topics: vaccination, diarrhoeal disease, iodine deficiency and other related problems. The World Vision's family health education section focused on the benefits of breast-feeding.

Individual health care in adolescent life is a very important matter which has been explicitly addressed in their curricula of BRAC, FDSR, FPSTC and World Vision. BRAC in its curriculum listed illness and contiguous diseases while FDSR curriculum emphasized on healthy habits, hazards of smoking and drinking alcohol and ways of overcoming these problems.

\subsection{Food and Nutrition}

Several organizations included in their curricula the following topics: importance of food items, disease caused by malnutrition, requirement of food according to age and activities etc.

\subsection{Reproductive Health}

Seventy percent of the curricula included different aspects of reproductive health, like

(1) mental and physical changes during puberty,

(2) mental and physical changes of boys and girls,

(3) reproductive organs,

(4) birth mystery and conditions of human birth,

(5) menustration etc. ICDDR,B, FPSTC, FPAB, CDS and CMES have explained openly the menustration process in their respective curricula. BRAC in its health-education curriculum has emphasized on physical care at menustration time, consumption of nutritious food, personal cleanliness, and early marriage. Sexuality, perversion, prevention and remedies of sexual diseases have been expounded by the curricula of CDS and ICDDR,B. Issues related to menopause, reproductive health, mental and physical changes have been discussed only by ICDDR,B and FPSTC.

Another side of the reproductive health is "sterility" which has been discussed by CMES and FDSR. These two curricula while discussing reproductive health explain beautifully that empowerment of women can ensure reproductive health for women.

\subsection{Family Life and Environment}

Adolescent family life education begins from family so by excluding family and family life education AFLE program can never be successful. Six organizations namely, FPAB, FDSR, BRAC, CDS, UCEP and CMES have provided information on this topic in their curricula. Their curricula focus on definition of family, its importance, types of family in Bangladesh, formation of small family etc. Among the six organizations working in this area, CDS and FPAB have specially emphasized on family life-cycle while FDSR and UCEP have laid special 
emphasis on the manners of children within family environment. FDSR has illustrated the role and responsibility of a young man towards his wife and children. On the other hand, the curriculum of CMES has excellently demonstrated the family life of females, place of female in her paternal abode, in her husband's domicile, identified role of women within the family and domestic responsibilities of women-women the sole worker etc.

\subsection{Female Education/Rules and Regulation}

Mainly five organizations: FDSR, WV, CMES and FPSTC have addressed this topic in their respective curricula. Each organization has incorporated the main objective of female education, importance of female education and female status in their curriculum. WV and CMES provided detailed explanation of the ways of enhancing female honor and dignity. CMES curriculum contains a clear documentation of female right while FDSR documented the case of women's right in different occupations, rules and regulations applicable to them.

\subsection{Population Education}

This topic has mostly been discussed in the curriculum of those organizations who deliver FP$\mathrm{MCH}$ services, such as- FPAB, FPSTC, CDS and FDSR. Each of their curriculum focuses on definition of population, present condition of population, and population control methods. FPAB curriculum provides the most elaborate explanation on this issue.

\subsection{Family Planning}

The curricula of FPSTC, FPAB, CDS, ICDDRB and CMES contain elaborate discussion on family planning. The topics that were given prominence are: an overall idea about family planning, methods of family planning, rules of using family planning methods, effectiveness and possible side-effects of contraceptive methods.

\subsection{Primary Education}

Primary education in both forms: formal and non-formal is very important for AFLE program. Without education, AFLE can never be successfully implemented. BRAC, Ahsania Mission, FPAB and CMES, provide education on Bengali language, Mathematics, Environment, Health and Social consciousness through non-formal instruction system. WV provides emphasis on AFLE under the sponsorship program. 


\subsection{Health and Environment}

Within the socio-economic context of Bangladesh, education on our nature, soil, water, plants, animals etc. is very necessary for the adolescents of this country. The curricula of BRAC, WV and FDSR have attached special importance on the plantation of trees, housing, proper disposal of garbage and human wastes.

\subsection{Self-Employment and Income Generation}

To increase adolescent self-reliance different types of training on small and cottage industry activities, poultry farming, cultivation, improved hearth etc. have been discussed specially in the curricula of FDSR, CMES and Ahsania Mission.

\subsection{Women's Financial Self-Reliance}

CMES is the only organization who has addressed this issue in its own curriculum. It has discussed about both technological and entrepreneurial efficiency, credit programs for adolescents girls etc.

\subsection{Mental Health}

This issue has been incorporated as a part of AFLE curriculum only by WV. It has highlighted topics like: barriers towards mental well-being during adolescence and ways of overcoming these obstacles.

\subsection{Child Right}

UCEP alone has highlighted child right issues in its AFLE curriculum. Several child rights issues have been incorporated in the curriculum such as food, health, education, entertainment, sports, and security.

\subsection{Subjects for Learning}

The AFLE curriculum of FDSR contains a beautiful description of this issue. The issues that every citizen requires to know in daily life have been described in this curriculum. These issues include: dress, behavior, first-aid treatment in case of burns/cuts/heart attack/snakebite/dog-bite, life-saving measures, such as-drowning etc.

\subsection{Personality and Cultural Development}

The necessary measures for fullfledged personality development of adolescent girls have been incorporated in the CMES curriculum. The aspects emphasized are: conversation, behavior, movement, taste and courage.

\subsection{Female-Male Disparity}


A detailed description of this topic is offered by the CMES curriculum. The issues discussed within this topic are: female-male disparity in the spheres of family, education, employment, and work-arena.

A description of the main topics discussed in the curricula used by different organizations has been provided below. The following tables are constructed according to the program demands and importance of issues in relation to different organizations.

\section{Table-5}

The main issues addressed in Adolescent Life Education programs of voluntary organizations are described in the following tables. 
Table 5.1

Social Law, Right and Values

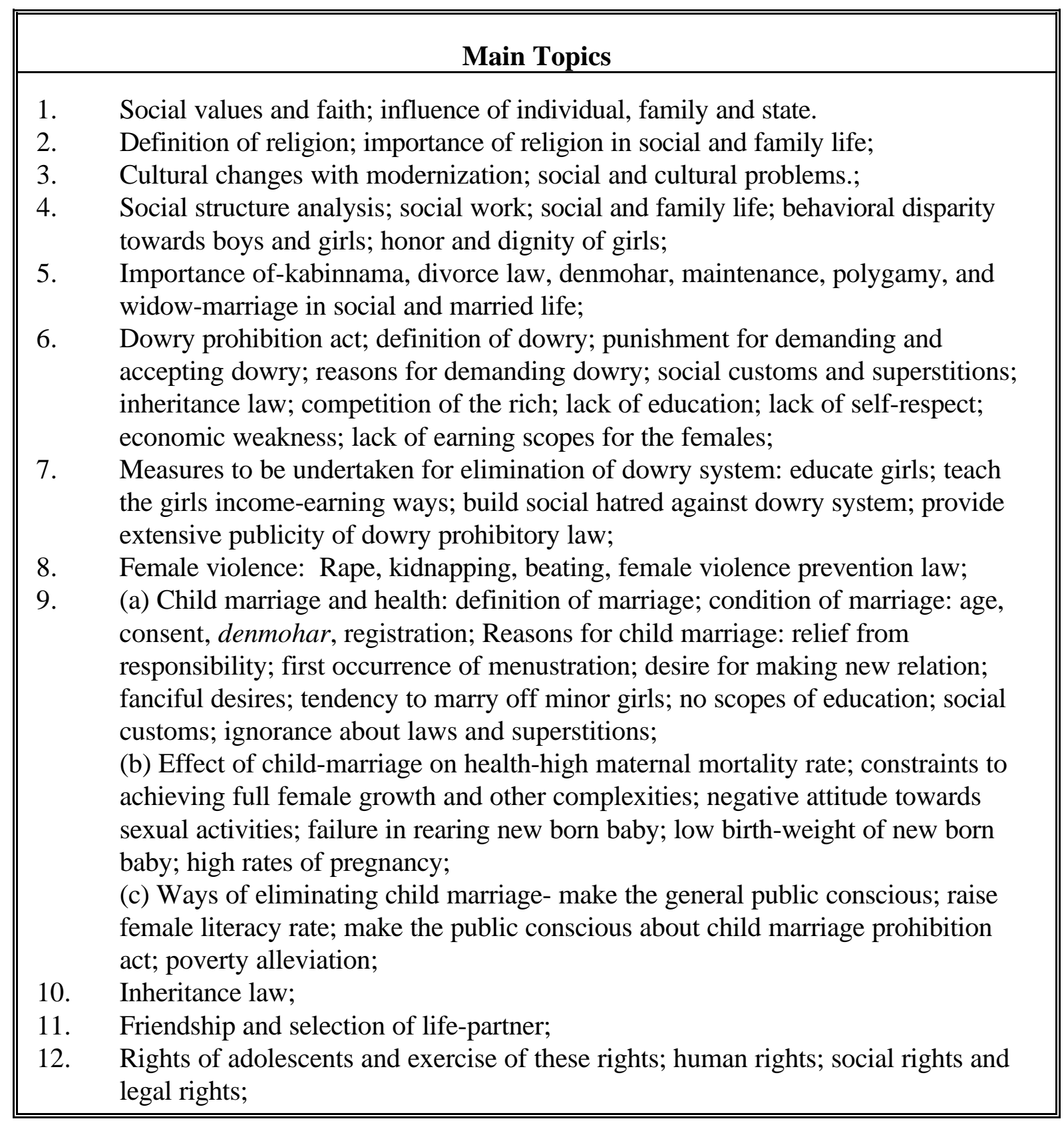


Table 5.2

General Health Education

\begin{tabular}{||l}
\hline \hline \multicolumn{1}{|c||}{ Main Topics } \\
\hline 1. \\
What does health mean; need for sound health; overall health situation of \\
Bangladesh; \\
Eight elements of primary health education: (a) health education; (b) food and \\
nutrition; elements of food; (c) primary cleanliness and safe water; (d) extended \\
vaccination program; (e) family planning; maternal and child health services; care \\
of pregnant woman and maternal care; (f) control of endemic diseases; (g) different \\
types of first-aid treatment and its necessity and objective; responsibilities and \\
duties of health workers; care of new born baby and baby food; (h) supply of life- \\
saving medicines; \\
Sewerage system; sanitary latrine and clean household; \\
Primary idea about health: \\
(a) personal health-care at the adolescent stage, care of: teeth, eyes, hair, nail, bath, \\
clean apparel, care of feet and skin etc.; (b) intestinal worms and preventive \\
measures; (c) diarrhoea and preventive measures; (d) safe water; (e) disease \\
preventing vaccination; name of diseases; immunization centers; (f) breast milk for \\
baby; benefits of breast-feedings techniques of breast feeding for a longer period; \\
(g) healthy habits - rest, sleep, labor, meal, recreation, games and physical \\
exercises; (h) few contagious diseases-jaundice, skin disease, chicken pox, common \\
cold and fever, conjuntivities and intestinal worms; (i) harmful effects of drinking \\
alcohol, smoking and drug abuses and ways of overcoming these bad habits;
\end{tabular}

Table 5.3

Food and Nutrition

\begin{tabular}{||cl||}
\hline \hline & \multicolumn{1}{|c||}{ Main Topics } \\
\hline \hline & \\
1. & Necessity of nutritious food for the adolescents; \\
2. & Classification of food-balanced diet; protein; carbohydrate; oil/ fat; \\
3. & Vitamin; \\
4. & Mineral salts-iron; calcium; iodine; \\
5. & Diseases caused by malnutrition-blindness from malnutrition; iodine deficiency \\
& related problems; night blindness; anemia; \\
6. & Nutritious food at lower cost; \\
7. & Requirement of food according to age and activities; \\
8. & Daily food list of an adolescent girl and young boy; \\
9. & Proper cooking methods; methods of preserving food; \\
10. & Three malnutritional diseases of child-marasmus, kwashiorkor, night blindness; \\
\hline \hline
\end{tabular}


Table 5.4

Reproductive Health Education

\begin{tabular}{|c|c|}
\hline \multicolumn{2}{|r|}{ Main Topics } \\
\hline 1. & $\begin{array}{l}\text { The mystery of human birth; role played by parents i.e. father and mother in } \\
\text { determination of sex: } x x \text { for girls and xy for boys; }\end{array}$ \\
\hline 2. & $\begin{array}{l}\text { What happens at puberty; time of puberty; physical changes, mental health and } \\
\text { emotional problems of boys and girls during puberty; Discussion on external } \\
\text { physical changes of boys and girls aged 9-10 years; effect of hormone on this } \\
\text { changes; male and female reproductive systems; }\end{array}$ \\
\hline 3. & Hymen; \\
\hline 4. & $\begin{array}{l}\text { Breast development-different stages of breast development; growth of hair in the } \\
\text { vaginal zone; external female sex organs; internal female sex organs and illustrated } \\
\text { analysis of different female organs; }\end{array}$ \\
\hline 5. & $\begin{array}{l}\text { Reasons for menustration-hormonal effects behind menustration; physical condition } \\
\text { during menustration; cleanliness; things to be avoided during menustration; } \\
\text { nutritious food and self-care; }\end{array}$ \\
\hline 6. & $\begin{array}{l}\text { Changes in boys-changes in boys due to hormonal effect (illustrated description). } \\
\text { At adolescent stage boys are able to produce baby. Circumcision; illustrated } \\
\text { description of male sex organs before and after circumcision; penis and illustrated } \\
\text { description of penis; change of voice; muscle and other changes; pubic hair; hair } \\
\text { beneath armpit; physical hair; beard; }\end{array}$ \\
\hline 7. & $\begin{array}{l}\text { Pregnancy-symptoms of pregnancy; care of pregnant woman; breast feeding; } \\
\text { sterility; }\end{array}$ \\
\hline 8. & $\begin{array}{l}\text { Menopause of women-mental and physical changes of women at this time; } \\
\text { solution; }\end{array}$ \\
\hline 9. & $\begin{array}{l}\text { Sexuality-a scientifically normal feature of human life but forceful physical } \\
\text { relationship is illegal and disrespectful; }\end{array}$ \\
\hline 10 . & $\begin{array}{l}\text { Sexually transmitted diseases-Gonorrhea, Syphilis, aids. Condoms provide an } \\
\text { effective safe-guard against STDs. }\end{array}$ \\
\hline 11. & $\begin{array}{l}\text { Self-care: notice regularity of menustration; give importance to discomforts; always } \\
\text { drink enough water and not suppress urine when in pressure; check breast regularly } \\
\text { each month for probable tumour lump (illustrated description); }\end{array}$ \\
\hline
\end{tabular}


Table 5.5

Family Life and Environment

\begin{tabular}{|c|c|}
\hline \multicolumn{2}{|r|}{ Main Topics } \\
\hline 1. & $\begin{array}{l}\text { (a) Family; (b) types of family in Bangladesh; (c) need for family; (d) family rights } \\
\text { and responsibility; }\end{array}$ \\
\hline 2. & $\begin{array}{l}\text { (a) Family life cycle-husband-wife relation; contention; reasons of conflict and } \\
\text { ways of overcoming it; (b) healthy family ensures a good life; }\end{array}$ \\
\hline 3. & Need of small family and ways of forming small family; \\
\hline 4. & $\begin{array}{l}\text { Role of family members (mother, father, brother, sister) and mutual responsibilities } \\
\text { and duties; }\end{array}$ \\
\hline 5. & Behavior of boys and girls within family environment; \\
\hline 6. & $\begin{array}{l}\text { Responsibility and duties of adolescents towards their family members; } \\
\text { responsibility and duties of husband towards their wife and children; }\end{array}$ \\
\hline 7. & $\begin{array}{l}\text { Family life of women-role of women in formation of family (present status); (a) } \\
\text { parent's family;(b) husband's family;(c) proper place of women in family; (d) } \\
\text { household chores-women the sole worker; }\end{array}$ \\
\hline
\end{tabular}

Table 5.6

Female education, Rules and Regulation

\begin{tabular}{||l||}
\hline \hline \multicolumn{1}{|c||}{ Main Topics } \\
\hline 1. \\
Main objective and necessity of female education: \\
Methods of developing self-reliance, honor and dignity by females for themselves; \\
(a) formal and non-formal education; (b) technical dexterity and trade skill; (c) \\
financial self-reliance; (d) consciousness about female rights and implementation; \\
human rights; social rights; legal rights; (e) female job priority higher in different \\
professions; (f) rules and regulation for adult women and young girls-marriage; \\
remarriage; divorce and widow-marriage;
\end{tabular}

Table 5.7

Population Education

\begin{tabular}{||ll||}
\hline \hline & \multicolumn{1}{c|}{ Main Topics } \\
\hline \hline 1. & $\begin{array}{l}\text { Definition of population; population growth and decline; population explosion and } \\
\text { problems of population growth in Bangladesh; land space and population growth }\end{array}$ \\
& 50 years back; land space and population growth 50 years hence; apparel; housing; \\
& treatment; education; child labor; food and nutrition; environment; unemployment; \\
& family and social \& cultural problems; \\
2. & Population control-population decline due to natural causes; planned family; \\
3. & Measures to be followed as solution to population problem; family planning; \\
4. & Crude birth rate and crude death rate, population growth rate; \\
5. & Importance of population education in the context of Bangladesh; \\
6. & Dissemination of population education through trained youth leaders; \\
\hline \hline
\end{tabular}


Table 5.8

Family Planning

\section{Main Topics}

1. Necessity of family planning program in Bangladesh-what is family planning; relationship of family planning with maternal well-being and child-health;

2. Family planning methods: safe period; withdrawal; condom (male); foam tablet (female); copper-T (IUD); injection (2 types), depo-provera (3 months), norestrate (2 months); NORPLANT; oral birth control pills; menustration regulation (MR); vasectomy (male); ligation (female);

3. Use; effectiveness and side-effects of these family planning methods have been explained clearly in details through charts;

Table 5.9

Primary Education

\begin{tabular}{||ll|}
\hline \hline \multicolumn{1}{|c|}{ Main Topics } \\
\hline \hline 1. & $\begin{array}{l}\text { Subjects taught through primary education are: Bengali, mathematics, introduction } \\
\text { to environment, health education, learning to read, write and sign etc.; }\end{array}$ \\
2. & $\begin{array}{l}\text { Information about Bangladesh; } \\
\text { Teaching Bengali language and mathematics through charts and develop social } \\
\text { consciousness; }\end{array}$ \\
\hline
\end{tabular}

Table 5.10

Health and Environment

\begin{tabular}{|c|c|}
\hline & Main Topics \\
\hline 1. & $\begin{array}{l}\text { Natural environment-soil; water; plants; environmental pollution and our } \\
\text { responsibilities; conditions of plantation; selection of sites for planting trees; } \\
\text { sapling nursery; general rules of tree plantation; sapling care; production of sapling } \\
\text { and our socio-economic context; }\end{array}$ \\
\hline 2. & Trees in environmental development; \\
\hline 3. & Housing in environmental development; \\
\hline 4. & Disposal of garbage and environmental development; \\
\hline 5. & Disposal of human wastes and environmental development; \\
\hline
\end{tabular}


Table 5.11

Self-employment and Income-generating Project

\section{Main Topics}

1. Small and cottage industry;

2. Poultry farming;

3. Cultivation;

4. Improved hearth;

5. Collection of legitimate wage;

6. Family vegetable garden;

7. Farming of koyl and pigeon;

8. Fish Farming;

Table 5.12

Financial Self-reliance of Women

\begin{tabular}{||ll||}
\hline \multicolumn{1}{|c||}{ Main Topics } \\
\hline \hline $\begin{array}{l}\text { 1. } \\
\text { 2. }\end{array} \quad \begin{array}{l}\text { Technological dexterity and trade skill.; } \\
\text { Knowledge about market demand: } \\
\text { places where quality goods are available at cheaper price; knowledge on marketing } \\
\text { channels enables to derive higher profits; methods of quality control of goods; } \\
\text { ways of cheaper and higher production; chain system of commodity production; } \\
\text { Credit for adolescents-objective of adolescent credit program; formation of group; } \\
\text { revolving fund; overdue; group fund; types and terms of credits; service charges; }\end{array}$ \\
\hline
\end{tabular}


Table 5.13

Mental Health

\begin{tabular}{|c|c|}
\hline & Main Topics \\
\hline 2. & $\begin{array}{l}\text { Mental health in adolescent life-general health is related to mental well-being; } \\
\text { constraints towards mental well-being; lack of education opportunity inspite of } \\
\text { willingness of the candidate; neglect of parents, marriage of immature girls by the } \\
\text { guardians inspite of their disapproval; family restrictions towards liking/love; } \\
\text { Ways of preserving mental health-individual discipline; family discipline; religious } \\
\text { morals; life-sketch of celebrities; no anxiety and tension; balanced diet and regular } \\
\text { exercise; }\end{array}$ \\
\hline
\end{tabular}

Table 5.14

Child Right

\begin{tabular}{||l||}
\hline \multicolumn{1}{|c||}{ Main Topics } \\
\hline \hline $\begin{array}{l}\text { A few child rights-food; health; education; recreation and games; rights to be } \\
\text { protected from commercial and sexual exploitation; rights of refusal to participate } \\
\text { in war or any other kind of combats; rights of protection from mental and physical } \\
\text { abuse; }\end{array}$ \\
\hline
\end{tabular}

Table 5.15

Subjects for Learning

\begin{tabular}{|c|c|}
\hline & Main Topics \\
\hline $\begin{array}{l}2 . \\
3 .\end{array}$ & $\begin{array}{l}\text { Knowledge required in daily life-behavior; dress and appearance; first-aid } \\
\text { treatments in case of burns/cuts/falls/entry of alien objects in the eyes/injury to } \\
\text { head/entry of alien object in the ears/heart attack; } \\
\text { Snake bite; animal bite; life-saving measure in case of drowning victim; } \\
\text { Liquid mixture of salt and molasses or oral saline and immunization; }\end{array}$ \\
\hline
\end{tabular}

Table 5.16

Personality and Cultural Development

\begin{tabular}{||l||}
\hline \multicolumn{1}{|c||}{ Main Topics } \\
\hline $1 . \quad \begin{array}{l}\text { Overall personality development of adolescents-conversation; behavior; movement; } \\
\text { taste; enthusiasm and courage; agility and persevering attitude; development of } \\
\text { cultural and sports capacity; }\end{array}$ \\
\hline
\end{tabular}


Table 5.17

Female-male disparity

\begin{tabular}{||ll||}
\hline \multicolumn{1}{|c||}{ Main Topics } \\
\hline \hline 1. & Socialization to eliminate female-male disparity: role of family in socialization; \\
2. & Socialization in education-formal education; non-formal education; informal \\
& education; \\
3. & Socialization method among classes; \\
4. & Socialization method in employment sphere; \\
5. & Socialization in law and religious sphere; \\
6. & Socialization through literature; \\
\hline \hline
\end{tabular}




\section{Chapter Five}

\section{CONCLUSION}

The adolescent life education program is a new addition for Bangladesh. The organizations involved in this field have received excellent response in their respective project areas. On the other hand, according to AFLE program need some curricula have been prepared in Bengali which will help new organizations in running their future AFLE activities.

It is evident from the evaluations done in the previous chapters that AFLE program has never been effective as a single system rather it has always been initiated with other programs like formal-non-formal education, family planning service and research, family development services etc. The evaluation of AFLE program has revealed that it can be run along with any other programs but it may be experimentally implemented to test whether this program can run by itself or some problem may arise for its sole running alone.

The evaluation of the present AFLE program of Bangladesh underscores the need for evolving uniform projects in this field. It also emphasizes the need for inclusion of those issues which are immensely important for Adolescent Life Education. While evaluating the AFLE program, it was observed that the program was connected with other programs at the implementation stage, like formal non-formal education, family planning etc. Therefore it may be concluded that AFLE program can be carried out along with other activities.

Furthermore, the problems of adolescent life should be an integral part of the AFLE program so that the adolescents educated under this program can tackle the problems with selfconfidence.

\section{Recommendation}

The findings suggest that a curriculum needs to be developed which will include all the subjects that the adolescents are required to know in Bangladesh. To run a uniform AFLE program in Bangladesh the list of issues that are required to be incorporated in the curriculum is given below. The evaluating team recommended that these issues should be integrated into the following eight groups.

\subsection{Family and Family Life}

Definition of family and family life; types of family in Bangladesh; need for family; Role of family members and mutual responsibilities; duties;

Family life-cycle;

Need of maintaining small family and ways of forming small family;

Behavior of boys and girls in family life; responsibilities and duties;

Role of women in formation of family;

\subsection{Social Laws, Rights and Values}


Social values and faith; influence of individuals, family, and state;

Definition of religion; importance of religion in family and social life;

Cultural changes with modernization-cultural and social problem;

Analysis of social structure; honor and dignity of women; female-male disparity; oppression of women;

Marriage; and the importance in social life;

Dowry;

Child marriage and its repercussion on health;

Social laws:

(a) child marriage prohibition act; (b) divorce law; (c) muslim marriage and divorce law; (d) denmohar and maintenance; (e) female violence prevention act; (f) dowry prohibition act; (g) inheritance law;

Friendship and selection of life-partner;

Primary education;

Child right;

\subsection{Reproductive Health}

Mysteries of human birth;

Determination of boys and girls: explanation of $\mathrm{xx}$ and $\mathrm{xy}$ chromosomes;

Time of puberty; mental; physical and emotional changes of boys and girls in adolescent stage; female-male reproductive system;

Breast development and other physical changes;

Menustration;

Physical changes in boys;

Pregnancy; care of pregnant women; sterility;

Menopause;

Sexuality;

Sexually transmitted diseases;

Self-care;

\subsection{General Health Education, Health and Nutrition}

Definition of health; need of maintaining sound health; overall health situation of Bangladesh;

Eight elements of primary health care;

Disease preventing vaccination; name of diseases; immunization centers;

Diarrhoea preventing ways; intestinal worms and iodine deficiency related problems;

Personal health care in adolescent life;

Sanitation and sanitary latrine;

Breast milk for baby; benefits of breast feeding;

Diseases and contagious diseases;

Healthy habits of adolescent life;

Harmful effects of drinking alcohol, smoking and drug abuses; ways of overcoming these bad habits;

Necessity of nutritious victuals for adolescents;

Classification of food; 
Vitamins;

Mineral salts;

Malnutrition; diseases caused by malnutrition;

Daily food list of adolescent girls/boys;

Nutritious food at lower cost; proper cooking methods;

Methods of food preservation;

\subsection{Population Education and Family Planning}

Definition of population; population growth and decline; population explosion;

Population growth related problems of Bangladesh;

Population control;

Primary concept about family planning:

safe period; withdrawal; condom (male); foam-tablet (female); IUD -two types of injection: depo-povera (3 months); norestrate (2 months); NORPLANT; oral birth control pills; menustration regulation (abortion); vasectomy (male); ligation (female); use of family planning methods; side-effects;

\subsection{Mental Health \& Environment and Health}

Mental health in adolescent life; relationship of health with mental condition; constraints of mental well-being;

Ways of maintaining mental well-being;

Natural atmosphere;

Environmental pollution and our responsibility;

Tree in environmental development; housing; disposal of garbage; disposal of human waste;

\subsection{Self-employment, income generating project and Financial Self-Reliance}

Income generating projects: small and cottage industry; poultry farming; cultivation; improved hearth; family vegetable garden; farming of koyl and pigeon; fish farming; collection of legitimate wage;

Technological dexterity and trade skill;

Market demand;

Credit system;

\subsection{Personal and Cultural Development}

Conversation;

Behavior;

Movement;

Taste;

Enthusiasm and courage;

Agility and persevering attitude;

Development of cultural and sports capacity; 
The integration of the above mentioned subjects in the AFLE may lead to the successful implementation of the AFLE program in Bangladesh. This will eventually enable the program to improve the life style of the people of this country. Moreover, enormous strength and potentiality are hidden among the adolescents. Effective utilization of this latent strength through successful and effective implementation of the AFLE program can help the country enormously in its development process.

The adolescents of today are parents of tomorrow. What they will learn now will be applied by them later in different spheres of their lives. This reason underscores the need for a broad expansion of this education program in Bangladesh. 


\section{Book List}

1. School Bohirvuto and School Paritage Jubokder Janasanka Sikha Pathakram, Bangladesh Family Planning Association, Walliullah M. and Khalikuzzaman S. M., Dhaka, 1988, P-58.

2. Sachitra Janasanka Sikha Sahaika, Bangladesh Family Planning Association, Rahman M. and Jalil S. Dhaka, 1988, P-45.

3. Samaj Sikha Kendrer Sahaika, Bangladesh Family Planning Association, Edited by Jalil S. Dhaka, 1989, P-42.

4. Kishori Mayeder Janya Paribarik Jiban Sihkha: Prashikan Manual, Center for Development Services, Akhter J., Dhaka, 1993, P-112.

5. Paribarik Jibon Sikha Sahaika, Flipchart, Center for Development Services (CDS), Chowdhury F. O., Dhaka, 1994, P-17.

6. Sustha Paribar Sundar Jibon, Center for Development Services (CDS), Akhter J. and Hamid M. A., Dhaka, 1994, P-78.

7. Sastha Samaj O Bigan: Pancham Sreni, Upokoron Unnayan Sadaharan Sikha Karjakram UCEP-Bangladesh, Liaquat N. Dhaka, 1995, P-35.

8. Sastha Samaj O Bigan: Chaturtha Sreni, Upokoron Unnayan Sadaharan Sikha Karjakram UCEP-Bangladesh, Liaquat N. Dhaka, 1995, P-21.

9. Sastha Samaj O Bigan: Treetio Sreni, Upokoron Unnayan Sadaharan Sikha Karjakram UCEP-Bangladesh, Liaquat N. Dhaka, 1995, P-35.

10. Sastha Samaj O Bigan: Detiya Sreni, Upokoron Unnayan Sadaharan Sikha Karjakram UCEP-Bangladesh, Liaquat N. Dhaka, 1995, P-28.

11. Sastha Samaj O Bigan: Pratham Sreni, Upokoron Unnayan Sadaharan Sikha Karjakram UCEP-Bangladesh, Liaquat N. Dhaka, 1995, P-26.

12. Koishor Jibon Sikha: Seminar Pratibedon, 14-15 July, Voluntary Health Services Society (VHSS), edited by Nasiruddin, Dhaka 1994, P-50.

13. Koishor Jibon Sikha: Anchalik O Jatiya Alochana Sabha 1994 Pratibedon, Voluntary Health Services Society (VHSS), edited by Dr. Nasiruddin, Dhaka 1994, P-53.

14. Prashikhak Proshikhon Sahaika Koishor Jibon Sikha, Voluntary Health Services Society (VHSS), edited by Nasiruddin, Dhaka 1994, P-87.

15. Esho Ganit Shikhi: Detiyo Vagh, Prathomik Sikha Karjokram, BRAC, Dhaka 1993, P-100. 
16. Esho Ganit Shikhi: Tretiyo Vagh, Prathomik Sikha Karjokram, BRAC, Dhaka 1993, $\mathrm{P}-88$.

17. Esho Pori: Prothom Vagh, Prathomik Sikha Karjokram, BRAC, Dhaka, 1993, P-52.

18. Esho Pori: Detiyo Vagh, Prathomik Sikha Karjokram, BRAC, Dhaka, 1992, P-57.

19. Esho Pori: Tretiyo Vagh, Prathomik Sikha Karjokram, BRAC, Dhaka, 1992, P-57.

20. Esho Pori: Prothom Vagh, Prathomik Sikha Karjokram, BRAC, Dhaka, 1994, P-56.

21. Paribesh Parichite: Tretiyo Vagh, Prathomik Sikha Karjokram, BRAC, written by Anwar S.N, Dhaka, 1994, P-71.

22. Amader Sastho: Detiyo Vagh, Prathomik Sikha Karjokram, BRAC, Dhaka, 1992, P48.

23. Esho Pari: Detiyo vagh, Prathomik Sikha Karjokram, BRAC, edited by Begum I. N., Dhaka, 1994, P-60.

24. Amader Bigan: Pancham Parbo, Prathomik Sikha Karjokram, BRAC, written by Abdal S.N, Dhaka, 1994, P-46.

25. Amader Bigan: Chaturtho Parbo, Prathomik Sikha Karjokram, BRAC, written by Abdal S.N, Dhaka, 1994, P-68.

26. Paribesh Parichiti: Chatutho Parbo, Prathomik Sikha Karjokram, BRAC, written by Islam R. M., Dhaka, 1994, P-43.

27. Paribesh Parichiti: Panchom Parbo, Prathomik Sikha Karjokram, BRAC, written by Islam R. M., Dhaka, 1994, P-40.

28. Sikha Prashikhon Sahahika (Refreshers) Detiyo o Tretiyo Srenir Janyo, Prathomik Sikha Karjokram, BRAC, Dhaka, 1995, P-42.

29. Ganit Shikhi: Prathom Vagh, Prathomik Sikha Karjokram, BRAC, Dhaka, 1994, P152.

30. Prastuti Prabo: Kishore Kishori, Prathomik Sikha Karjokram, BRAC, Dhaka, 1993, P-31.

31. Sikhok Proshikhok Sahahika: Maulik Proshikhon, Prathomik Sikha Karjokram, BRAC, edited by Dr. Sudir Chandra Sarkar, Vivakanand Hawaladar, Dhaka, 1994, P-71. 
32. Paribesh Parichiti: Prothom Vagh, Prathomik Sikha Karjokram, BRAC, edited by Hawaladar V., Dhaka, 1993, P-84.

33. Kishore Path-Prathom Khando: Sebok Nirdeshika, Dhaka Ahsania Mission, Dhaka, 1993, P-103.

34. Kishore Path-Prathom Khando: Sebok Nirdeshika, Dhaka Ahsania Mission, Dhaka, 1993, P-108.

35. Kishore Path-Detiyo Khando: Upokaran Unnayan Bivagh, Dhaka Ahsania Mission, Dhaka, 1993, P-129.

36. Kishore Path-Prathom Khando: Upokaran Unnayan Bivagh, Dhaka Ahsania Mission, Dhaka, 1993, P-110.

37. Kishore Path-Tretiyo Khando: Upokaran Unnayan Bivagh, Dhaka Ahsania Mission, Dhaka, 1994, P-113.

38. Kishore Kishori Pathomala Prothom Khando: Sikhok Shahahika, Combined nonformal education program in assistance from UNICEF, Prathomik o Ganoshikha Bivagh, Dhaka, 1994, P-66.

39. Kishore Kishori Pathomala Detiyo Khando: Sikhok Shahahika, Combined non-formal education program in assistance from UNICEF, Prathomik o Ganoshikha Bivagh, Dhaka, 1994, P-19.

40. Kishore Kishori Pathomala Tretiyo Khando: Sikhok Shahahika, Combined non-formal education program in assistance from UNICEF, Prathomik o Ganoshikha Bivagh, Dhaka, 1994, P-16.

41. Kishore Kishori Pathomala Prathom Khando: Sikhok Shahahika, Combined nonformal education program in assistance from UNICEF, Prathomik o Ganoshikha Bivagh, Dhaka, 1995, P-118.

42. Kishore Kishori Pathomala Detiyo Khando: Sikhok Shahahika, Combined non-formal education program in assistance from UNICEF, Prathomik o Ganoshikha Bivagh, Dhaka, 1994, P-132.

43. Kishore Kishori Pathomala Tretiyo Khando: Sikhok Shahahika, Combined non-formal education program in assistance from UNICEF, Prathomik o Ganoshikha Bivagh, Dhaka, 1994, P-164.

44. Kishore Kishori Sikhakram: Maulik Sikha Samannito Upoanusthanik Sikha Bistar Karjokram, Primary and Mass Education Section, Dhaka, P-37.

45. Kishore Kishorider Janya Paribarikh Jibon Sikha Pathokram, Masud A. S. A. Voluntary Health Services Society (VHSS), Dhaka, 1994, p-150. 
46. Sarir Amar Sidhanto Amar Naripakho Urban Extension Project ICDDR, B.

47. Kishori Mayeder Janyo Paribarikh Jibon Sikha: Proshikhon Nirdeshika, Masud A. S. A Dhaka 1993, P-76.

48. FDSR: Barshik Pratibedon 1994, Dhaka, P-18.

49. Ay Chelera Ay Mayera: Book on male female equity for adolescents in Primary school system, Ibrahim and Banu,

50. Shikhak Sahahika : Sadaran Dharana, Sastha, Samaj O Bigan, Prothom Sreni, Detiyo Sreni, Tretiyo Sreni, Liaquat N. and Malek A. Upokaran Unnayan Sadharan Sikha Karjokram, UCEP-Bangladesh, Dhaka 1995, p-7.

51. Shikhak Sahahika : Sastha, Samaj O Bigan, Prothom Sreni, Liaquat N. and Malek A. Upokaran Unnayan Sadharan Sikha Karjokram, UCEP-Bangladesh, Dhaka 1995, p-34.

52. Shikhak Sahahika : Sastha, Samaj O Bigan, Detiyo Sreni, Liaquat N. and Malek A. Upokaran Unnayan Sadharan Sikha Karjokram, UCEP-Bangladesh, Dhaka 1995, p34.

53. Shikhak Sahahika: Sastha, Samaj O Bigan, Tretiyo Sreni, Liaquat N. and Malek A. Upokaran Unnayan Sadharan Sikha Karjokram, UCEP-Bangladesh, Dhaka 1995, p42.

54. Paribarik Jibon Sikha Pathokram Grameen Kishoreder Janno, Paribarik Jibon Bishayak Shikhar Pathoshuchi, Paribar Unnayan Sheba O Gabashana (FDSR), Dhaka, p-98.

55. Paribarik Jibon Shikha Pathokram Grameen Kishoreder Janno, Paribarik Jibon Bishayak Shikhar Pathoshuchi, Paribar Unnayan Sheba O Gabashana (FDSR), Dhaka, p-109.

56. Family Planning Association of Bangladesh (FPAB) Semi-Annual Report: JanuaryJune, 1994, Dhaka, p-14.

57. Non-formal Primary Education: Annual Report 1994, BRAC, Dhaka, p-49.

58. Assessment of Adolescent Family Life Education Programmes in Bangladesh, Rahman R and Chowdhury M, Voluntary Health Services Society (VHSS), 1994, Dhaka, p-21.

59. Workshop on Family Life Education, June 3-4, 1992, Manikgonj, Organised by VHSS and AFLE Forum. 
60. Annual Report 1993, Dhaka Ahsania Mission, DAM Publication: 57, 1994, p-41.

61. Assessment of the Strategy and Implementation of the Family Life Education Program of FPSTC supported NGO Projects in Bangladesh. Noor Mohammad. A paper prepared in partial fulfillment of the requirements for the degree of Master of Public Health (MPH) 1995. Department of Health Policy and Administration of the University North Carolina at Chapel Hill, USA. 


\section{APPENDIX 1}

\section{Glossary}

AFLE

FPSTC

UHEP, ICDDR,B

BRAC

WV

BASE

MJS

BUS

SGS

PUP

GKK

FF

INFEP

VHSS

BPHC

OMI

VIWF

BSSBG

FDSR

DMSS

FPAB

ASOD

CDS

MJSS

CDMS

CWFP

HB

TAF

AIDB

JTS

NM

TDHS

BWHC

MCI

CMES

AAF

NUS

$\mathrm{P}$

PRDA

UTPS

MHBO
Adolescent Family Life Education

Family Planning Services and Training Center

- Urban Extension Project, International Center for Diarrhoeal Diseases Research, Bangladesh.

Bangladesh Rural Development Advancement

Committee

- $\quad$ World Vision

- $\quad$ Bangladesh Association for Community Education

- $\quad$ Maler Hat Jub Sangha

- $\quad$ Bahumukhi Unnayan Society

- $\quad$ Saudan Gano Unnayan Sangstha

- $\quad$ Polli Unnayan Prochesta

- GanoKalyan Kendra

- $\quad$ Ford Foundation

Integrated Non-formal Education Program

- Voluntary Health Services Society

- $\quad$ Bangladesh Population and Health Consortium

- $\quad$ Organization for Mothers and Infants

- $\quad$ Visually Impaired Women's Forum

- $\quad$ Baptist Sangha School for Blind Boys

- $\quad$ Family Development Services and Research

Dustho Manob Sheba Sangstha

- $\quad$ Family Planning Association of Bangladesh

Assistance for Social Organizations and Development

- $\quad$ Center for Development Services

- $\quad$ Manikganj Janashankha Simitokaran Samity

Chinispur Dipshikha Mahila Samity

Concern Women for Family Planning

- $\quad$ Heed Bangladesh

- $\quad$ The Asia Foundation

- $\quad$ Associates for Integrated Development

- Jatiya Tarun Sangha

- $\quad$ Nari Maitry

- $\quad$ Trres Des Homes Switzerland

Bangladesh Women's Health Coalition

- $\quad$ Mina Communication Initiative

Center for Mass Education in Science

- $\quad$ Aids Awareness Foundation

- $\quad$ Nari Unnayan Shakti

- $\quad$ Pradipon

Population Research and Development Associates

- $\quad$ Unity Through Population Services

- $\quad$ Mossamat Hamida Begum Orphanage 


\begin{tabular}{|c|c|c|c|}
\hline NUK & & - & Nari Udog Kendra \\
\hline RDRS & & - & Rangpur Dinajpur Rural Service \\
\hline STC & & - & Save The Children-United State of America \\
\hline VIDA & & - & Village Integrated Development Association \\
\hline BMKS & - & \multicolumn{2}{|c|}{ Banachaya Mohila Kalyan Samity } \\
\hline $\mathrm{JC}$ & & - & Jagoroni Chakro \\
\hline JJS & & - & Gono-Unnayan Dhara \\
\hline SNS & & - & Adin Welfare Center \\
\hline MSS & & - & Manob Sheba Snagstha \\
\hline AIESDUP & & - & AIESDUP \\
\hline GJSKS & - & \multicolumn{2}{|c|}{ Gano Jagoron Samaj Kalyan Sangstha } \\
\hline SEDAB & & - & $\begin{array}{l}\text { Socio-economical Development Association } \\
\text { Bangladesh }\end{array}$ \\
\hline $\mathrm{CDC}$ & & - & Community Development Center \\
\hline FCDI & & - & Family and Child Development Institute \\
\hline BS & & - & Baikali Sangha \\
\hline BJ & & - & Banga Janani \\
\hline TVWO & & - & Tillotomma Voluntary Women's Organization \\
\hline TMSS & & - & Tanghamara Mahila Sabuj Sangha \\
\hline UDP & & - & Uttara Development Program \\
\hline GUA & & - & Gno Unnayan Accademy \\
\hline CWFP & - & \multicolumn{2}{|c|}{ Concern Women for Family Planning, Rajshahi } \\
\hline SBMSS & & - & Secchasebi Bahumukhi Mohila Samajkalyan Samity \\
\hline GKS & & - & Gano Kalyan Sangstha \\
\hline BPS & & - & Bangladesh Progoty Sangstha \\
\hline SU & & - & Swa-Unnayan \\
\hline PPC & & - & Palli Punargathan Club \\
\hline RDS & & - & Rural Development Society \\
\hline DAB & & - & Development Association of Barisal \\
\hline
\end{tabular}




\section{APPENDIX-2}

\section{Name of the organizations visited}

From 1st-30th August, 1995.

1. AVSC International

Dr. Abu Jamil Faisal

Country Representative-Bangladesh

House 275G (old)

2. The Asia Foundation (TAF)

Dr. N.S. Sadiq

Program Officer

House-2, Road-128

Gulshan, Dhaka 1212

3. Family Planning Services and Training Centre (FPSTC)

Mr. Abdur Rouf

Chief Executive

Noor Mohammad

Program Officer

103, New Circular Road, Dhaka-1

4. Family Planning Association of Bangladesh

Mr. Mizanur Rahman

Director General

Mr. Shoaib Jalil

Assistant Director Youth Director

2, Naya Paltan, Dhaka

5. Pathfinder International

Mr. Saiful Islam

Program Manager

House no 15, Road no 13A (New)

Dhanmondi R/A, Dhaka

6. ICDDR,B Urban MCH/FP Extension Project (UMCHFP)

Dr. Abdullah H. Baqui

Project Director

Ms. Jahanara Khatun

WFP Coordinator

Mohakhali, Dhaka 
7. Voluntary Health Services Society (VHSS)

Ms. Mayeeda Chowdhury

Incharge of AFLE Forum

273/274 Baitul Aman Housing Society

8. Family Development Services Research (FDSR)

Dr. Fatema Alauddin

Chairperson

House No.14, Road No. 125, Gulshan, Dhaka 1212.

9. World Vision of Bangladesh (WV)

Dr. Ratul Gopal Shah

Executive Director

House No. 27, Road No. 16 (New)

Dhanmondi R/A, Dhaka

10. Bangladesh Rural Advancement Committee (BRAC)

Ms. Kaneez Fatema

Primary Education

66, Mohakhali Commercial Committee, Dhaka

11. Concerned Women for Family Planning

Ms. Mufaweza Khan

Executive Director

Ms. Rokeya Sultana

Deputy Director

108, Kakrail Road, Dhaka

12. Ahsania Mission

Mr. Ehsanur Rahman

Deputy Director (Programs)

House No. 19, Road No. 12

Dhanmondi R/A

13. Ford Foundation

Ms. Gabriel Ross

Program Officer

House No. 30, Road No. 15 (New)

Dhanmondi R/A

14. United Nations Children's Fund

Ms. Mira Mitra

Communication

House No. 52, Road No. 4A (New)

Dhanmondi R/A

15. United Nations Fund for Population Activities (UNFPA) 
Ms. Tahera Ahmed

Sr. Program Officer

House No. 45, Road No. 3A

Dhanmondi R/A

16. Directorate of Family Planning

Mr. Nurul Amin

Director, IEM

Population Building, Azimpur, Dhaka

17. Directorate of Family Planning

Dr. Aminul Islam

Director, MCH

Population Building, Azimpur, Dhaka

18. Centre for Mass Education in Science

Dr. Muhammad Ibrahim

Executive Director

37/C Asad Avenue, Mohammadpur, Dhaka

19. Bangladesh Population and Health Consortium

NGO Project

Iftajul Haque Chowdhury

Project Coordinator, AFLE

38/1, Block F, Ring Road, Shymoli

20. Integrated Non-formal Education Program

Primary and Mass Education

Prof. Nilufar Rahman

Director, Curriculum

House No. 30, Road No. 8A

Dhanmaondi R/A

21. National Curriculum Text Board

Dr. M. A. Wahab

National Consultant

22. Center for Development Services (CDS)

Mr. Meher Ali Khan

Project Coordinator, AFLE

38/1 Block F, Ring Road, Shymoli 
23. Underprivileged Children's Educational Program (UCEP)

Ms. Nazma Liakat

Curriculum Specialist

Plot No. $2 \& 3$

Mirpur 2

24. TDH-Switzerland

Dhaka Program

Ms. Wahida Banu

2/5 Humayan Road, Block-B

Mohammadpur, Dhaka 


\section{APPENDIX-3}

\section{LIST OF MATERIALS ON AFLE}

1. Report on the National Workshop on Health Financing in the Voluntary Sector, held at Wildflower Halk, Shimal, May 1-4, 1990. Organized by Voluntary Health Association of India and Ford Foundation, New Delhi, VHAI, 1990, 34p.

2. Costs and Financing of Health Care: Experiences in the Voluntary Sector, Case Study 1: The Voluntary Health Services, Madras, New Delhi, Ford Foundation, 1990, 50p.

3. Costs and Financing of Health Care: Experiences in the Voluntary Sector, Case Study 2: SEWA Rural, Jhagadia Bharuch District, Gujurat, New Delhi, Ford Foundation, 1990, 44 (Acc No.536).

4. Costs and Financing of Health Care: Experiences in the Voluntary Sector, Case Study 3: Parivar, Seva Sangstha, New Delhi, Ford Foundation, 1990, 23p (Acc No.537).

5. Costs and Financing of Health Care: Experiences in the Voluntary Sector, Case Study 4: Ashish Gram Rachanan Trust (AGRT), Pachod, Maharastra, Delhi, Ford Foundation, 1990, 26p (Acc No.538).

6. Everything a Teenage Girl Should Know, John F. Knight, Victoria, Signs Publishing Company, 1982, 224p.

7. What a Young Woman Should Know About Sex. John F. Knight, Victoria, Signs Publishing Company, 224p.

8. What a Young Man Should Know About Sex. John F. Knight, Victoria, Signs Publishing Company, 219p.

9. So You Are a Teenager: Vital Facts for Boys. John F. Knight, Victoria, Signs Publishing Company, 1989, 192p.

10. School Sex Education: Why, What and How?: A Guide for Teachers/ Doreen E. Massey. London, Family Planning Association, 1988, 90p.

11. Love Needs Learning: A Relationship Course for Sixth-formers, London, The Catholic Marriage Advisors Council (CMAC), 1989, 90p.

12. Pregnancy and Childbirth/ Sheila Kitzinger, Revised edition, London, Penguin, 1989, 400p.

13. Girl or Boy? Your Chance to Choose: A Clear and Fascinating Examination of all the theories and techniques which could help you to choose your baby's sex/ Hazel Phillips with Tessa Hilton, London, THorsons, 1985, 96p. 
14. All About Sex/ Andrina E. Mc Cormac and Elizabeth McCall Smith, Edinburgh, Chambers, 1987, 42p. (Teenage Information Series).

15. Whats Happening to my Body?: A Growing Up Guide for Parents and Daughters/ Penguin, 1989, 273p.

16. Whats Happening to my Body?: A Growing Up Guide for Parents and Sons/ Lynda (Whith Dane Saavedra), London, Penguin, 1989, 263p. (Acc No. 950).

17. Greater Expectations: A Source Book for Working Witch Girls and Young Women/ Tricia Szirom and Sue Dyson, British Edition, edited by Hazel Salvin, Wishbech, Learning Development Aids (LDA), 1990, 196p.

18. Taught Not Caught: Strategies for Sex Education, The Clarity Collective/ Helen Myles, Wendy Gale, et. al. British edition edited by Hillary Dixon and Gill Mulliner Wishbech, LDA, 1990, 213p.

19. Sex Education Factpack, London, FPA Education Unit, 1988 (Sex and the Law, Why Sex Education?, Recent Legislation, Resources, Sex Education in Schools, Useful Agencies).

20. Assertion Training/ Anni Townsend, London, FPA, 1987, 50p.

21. Sharing: A handbook for those involved in Training in Personal Relationships and Sexuality/ Beryl Heather, London, FPA, 1987, 50p.

22. Family Life Education Curriculum Guidelines, New Delhi, Parivar Seva Sangstha, Family Life Education Project, 94p.

23. Counting the Costs of Adolescent Pregnancy, In "Youth and" Issue 2, March-June 1995, p.5.

24. Growing Up: Adolescence Body Change and Sex and Mariage, Susan Meredith, London, (Usborne facts of life), Usborne, 1987, 49p.

25. The Reproductive Health of Adolescence: A Strategy for Action, A Joint WHO/ UNFPA/UNICEF Statement, Geneva, WHO, 1989,18p.

26. Family Life Education/ UNESCO, Bangkok, 1991, 45p.

27. Learning Experiences in Population Education/ UNESCO, Bangkok, 1985, 111p.

28. Adolescence Education: Sexually Transmitted Diseases/ UNESCO, Bangkok, 1991, $45 \mathrm{p}$.

29. Child to Child: Approaches to Learning and Teaching/ Audrey Aarons, London, 33p. 
30. Publications and Documents: Division at Family Health/ WHO, Geneva, 1993, 11p.

31. Youth Programme Reviews: Family Planning Association of Kenya, Kirsten Hawkins, David Ojakaa, IPPF, Nairula, 23p.

32. Approaches to Adolescent Health and Development: A compendium of project and programmes/ WHO, Geneva 1992, 287p.

33. Evaluation of a Programme that Aims to Create Awareness About Height, Weight and Monitoring and Provide Health Education for Adolescents Girls in Bangladesh/ Christine Piper, A Dissertations, London, 1991, 112p.

34. Education to Prevent Aids/STDs in the Pacific: A Teaching Guide for Secondary Schools/ WHO, London, 1989, 87p.

35. Working with Uncertainty: A Handbook for Those Involved in Training on HIV and AIDs/ Hillary Dixon, Peter Gordon FPA, London, 1987, 50p.

36. Promotion of AFLE in Bangladesh: Proposal on Adolescent Family Life Education in Bangladesh through " Co-ordinations and Support Services to the NGOs Active in the Health Sector"/ Dr. Nasiruddin , VHSS, Dhaka. 1993.

37. Investigation of the Sanitary Protection, Needs of Poor Women in Bangladesh/ Naripakho, Dhaka, 1992, 38p.

38. First Inter-Africa Conference on Adolescent Health: Present and Future. Report of Activities/ Center for Population Opinion, New York, 1992,12p.

39. Family Life Education Materials: Selected Annotated Bibliography/ Programme Development Department of the IPPF International \Office London, 1984, 50p.

40. Influences on Adolescent Sexuality in Nigeria and Kenya: Findings from Recent Focus Group Discussions/ Gary Kanul and Susan Riqe/ Studies in Family Planning Vol. 23, Number 3, May/June 1992, Washington, 199-2/op.

41. A Brief Study on Adolescent Girls and Boys/ Conducted by Counselling Subcommittee: Ms. Fiona Duby, Ms. Gulshan Ara Chowdhury, Ms. Jacintha Quiah, Mr. Mahbubur Haque, 30p.

42. We Can, Because We think We Can: A Report of a Camp for Adolescent Girls/ Organized by Center for Health Education, Training and Nutrition Awareness (CHETNA), 1991, 25p.

43. Adolescent Reproductive Health in India: Needs Services and Approach: Report of a Residential Workshop/ Family Planning Association of India, Bombay, 1986, 33p. 
44. Voices for Choices: Sex Education Counselling Therapy Training/ Family Planning Association of India, Bombay, 1991, editor Mrs. Anne De Barganca Cunha, 93p.

45. Vision 2000: Strategic Plan/ International Planned Parenthood Federation, 1992, 32p.

46. Marriage and Social Alternatives for Mentally Handicapped/ Family Planning Association of India, Bombay, 1987,84p.

47. Adolescent Sexual and Reproductive Health: Report of the Workshop CIE, Paris, 811 July 1991/ editors Dr. Assia Bandrup-Lucknow, Sylvie Mansour, Kirsten Hawkins, $96 \mathrm{p}$.

48. The Family Life education Project in Fiji: A case study, Dr. Allan Kondo, UNESCO, Bangkok, Thailand, 1992, 10p.

49. Youth to Youth Project: ON Adolescent Reproductive Health Management/ Sierra Leone.

50. Needs and Availability of Nutrients for Adolescent Girls/ Shah Md. Keramat Ali, Md. Mokshed Ali Paramanik, Nasir Nahar Begum, Institute of Nutrition and Food and Science, Dhaka University, Dhaka, 8p.

51. Behavioural Problems in Older Children, The Journal of Family Medicine, VO1. 14, No.4, April 1989/ Peter Reder, Sean Maskey, London, 101-106p.

52. Basic Education Programme 1991-1995, Government of Bangladesh-UNICEF, Dhaka, 70p.

53. Health and Social Aspects of Adolescent Girls: A Qualitative Appraisal/ Chetna Team Gujrat, India 14p. 


\section{Appendix-4}

\section{LIST OF FORUM MEMBERS OF AFLE}

\section{Dhaka Division}

1. Ms. Gulshan Ara Chowdhury

Organization for Mothers and Infants (OMI)

265 Sher-e-Bangla Road, Zafarabad

Rayerbazar, Dhaka

2. Dr. A. M. Zakir Hossain

Office of the Directorate of Primary Health Care

Directorate of Heatlh Services

Mohakhali, Dhaka

3. Lina P. Chowdury

Visually Impaired Women's Forum

C/O HKI, House No. 40A Road No. 14 A

Dhanmondi, Dhaka

4. Mrs. Manju Samadder

Baptist Sangha Schools for Blind Girls

77, Senapara, Parbata, Mirpur-10, Dhaka

5. Md. Kasimuddin

Family Development Services and Research (FDSR)

216 Ashkona Jam-e-Masjid Road Uttara, Dhaka.

6. Md. Abdul Mannan

Dustha Manab Sebha Sangstha

Char Bhaga P. O. Dular Char, P. S. Vedargong

Shariatpur

7. Mohammmad Mohbub Alam

Family Planning Association of Bangladesh

2 Naya Paltan, Dhaka

8. Mahmuda Begum

Assistance for Social Organization and Development

11-17 R-12 Block-Kha, Pisciculture H. Society

Mohammadpur, Dhaka

9. Meher Dil Khan

Center for Development Services

38/1 Ring Road, Shymoli, Mohammadpur, Dhaka 
10. Murshida Khanam

Manikganj Janosankha Simitakaran Samity

Manikganj Town, Manikganj

11. Safura Begum

Chinishpur Deepshikha Mahila Shamity

Chinishpur P.O. Norshindhi College

Norshindi

12. Rokeya Sultana

Concern Women for Family Planning

108 Kakrail Road, Dhaka

13. Elgin Saha

Heed Bangladesh

P.O. Box-5052, New Market, Dhaka-1205

14. Dr. Najmun Nahar Sadiq

The Asia Foundation

House No. 2 Road No. 128 Gulshan Model Town

Dhaka-1212

15. Rina Das Gupta

Assosiation for Integrated Development Bangladesh

28/1 Ganaktully Pilkhana, Dhaka-1205

16. Md. Uddin Ahmed

Jatiya Tarun Sangha

21-23 Hazaribag Road, Dhaka-1209

17. A. K. M. Nurul Islam

Terres des Homes- Switzerland

2/5 Humayan Road, Block-B, Mohammadpur

Dhaka

18. Sharifa Begum

Nari Maitree

345/2 Goran, Dhaka 1219

19. Rebaka Sun-yat

Bangladesh Women's Health Coalition

House No. 46A, Road No. 6A, Dhanmondi R/A,

Dhaka-1209

20. Nuzhat Shehzadi

Meena Communication Initiative 
53 Mohakhali C/A

Dhaka-1212

21. Hasina Banu

Center for Mass Education in Science

37/C Asad Avenue, Mohammadpur

Dhaka

22. Dr. B. M. Rabiul Karim

Aids Awareness Foundation

House No. 293, Road No. 2 North Adabar

Shymoli, Dhaka

23. Afroza parvin

Nari Unnayan Shakti

253 Shipanibug, Khilgaon

Dhaka

24. Sultan Muhammad Razzak

Forum for Culture and Human Development

11/1 Kha Purana Palan Line

Dhaka 1000

25. Shamima Yesmin Alo

Prodipan

6/9 Lalmatia, Block-D, Dhaka-1207

26. Dr. Ladly K. Faiz

Population Research and Development Associates

House No. F-15, Road No. 4

Banani, Dhaka

27. Dr. Adina Azmiri

Bangladesh Population and Health Consortium (BPHC)

House No. 8, Road No. 12, Dhanmondi, Dhaka

28. Dr. Hasina Banu

Unity Through Population Service

House No. 15, Road No. 35, Sector-7

Uttara Model Town, Dhaka

29. Md. Ahmad Sikder

Mosammat Hamida Begum Orphanage

Vill. Charbaria, Nilphabaria

Goplaganj

30. Begum Fahmida Jigar Jahan 
Nari Uddug Kendra (NUK)

22/18 Khilji Road, Block-B,

Mohammadpur

Dhaka

31. Ms. Selina Shelly

Rangpur Dinajpur Rural Service (RDRS)

House No. 62, Road 7A, Dhanmondi R/A

Dhaka-1209

32. Kamal Hossain

Save The Children/ USA

House No. 35A, Road No. 9A, Dhanmondi R/A

Dhaka

33. Abdur Rouf

Family Planning Services and Training Centre (FPSTC)

103, New Circular Road, Dhaka.

\section{Khulna Division}

1. Md. Mahbubul Haque

Village Integrated Development Association (VIDA)

Post and Thana: Alamdanga

Kustia

2. Mrs. Ayesha Siddique

Banachaya Mahila Kalyan Samity

2, Boyra Cross Road, Sonadanga, Khulna

3. Mr. Mustafizur Rahman

Jagorani Chakra

44, Mujib Sarak, Jessore

4. A. T. M. Zakir Hossain

Jagarata Jubo Sangha

Hafiz Sarak, Talimpur Rupsha East

Khulna

5. Kaji Latifun Nesa (Tulip)

Gana Unnayan Dhara

78 HSS Road, Jhenidah

6. Dr. Aminur Rahman

Ad-din Welfare Centre

15 Jail Road, Jessore 
7. Khandakar Nuruzzaman

Samaj Nirman Sangstha

Village P. O. Box Kulshi Basha P.S. Kumarkhali,

Kustia

8. Lutfur Rahamn

Manob Seba Sangstha

Hospital Road, Keshabpur

Jessore

9. A. T. M. Wahiduzzaman

Socio-economical Development Association of Bangladesh

Sher-e-Bangla Road, P.O. Box-9,

Jhinediah 7300 .

10. Mizanur Rahman

AIESDUP

Arrapur

Jhenidah 7300.

11. Md. Shamsul Alam

Gana Jagaran Samaj Kalyan Sangstha

Shahaid Mashiur Rahman Sarak (Upa Shahar Para)

Jhenidah 7300

\section{Chittagong Division}

1. Alpana Barua

Community Development Center

House No. 122/B, Road No. 6

Chadgaon Residential Area

P.O. Box 1067

Chittagong

2. Dr. Zobaida Hannan

Family and Child Development Institute

Kanai Kutir, Bhagichagaon, Station Road

Comilla

\section{Rajshahi Division}

1. Mojahidul Islam

Baikali Sangho

12 Monibazar, Kazihata

Rajshahi 
2. M. Enamul Haque

Banga Jananee

Charkadahaa Dharabarisha Gurudashpur

Natore

3. Murshida Morshed

Tilottama Voluntay Women's Organization

Rowshan Mahal, kazihutta

Rajshahi

4. M. Ismail hossain

Thengamara Mahila Sabuj Sangha (TMSS)

Rangpur Road

Gokul, Bogra

5. A.F.M. Akhteruddin

Utara Development Programme

Salandar

Thakurgaon

6. Md. Mafizur Rahman

Gono Unnayan Accademy

Post: Hat Gurudaspur

Thana: Gurudaspur

Natore

7. Taiyeba Islam

Concern Women for Family Plnning

Rajshahi

Talaimari (Shahid Minar)

P.O. Kazla

Rajshahi

8. Magfura Begum

Secchasebi Bohimukhl Mahila

Samaj Kalyan Somity

House no. F-753, Maipara

P.O. Gharpara

Rajshahi

9. Khandakar Salim Jahangir

Gono Kalyan Sangstha (GKS)

Thana Road, Tarash

Sirajganj

10. Md. Karim Baksha

Bangladesh Progoti Sangstha (BPS) 
Village and Post tarash

Sirajgonj

11. Ms. Kamrun Nahar

Shaw Unnayan

Sepoypara Rajshahi 6000.

\section{Barisal Division}

1. Abdul Matin Khan

Polli Punargathon Club

P.O. Bandaria Post Code: 8550

Pirojpur

2. A. K. M. Khaleque

Rural Development Society

P.O. Daspura P.S. Bauphal

Potuakhali

3. Anjali Mali

Development Association of Barisal (DAB)

Monir Manjil, Norht Bogra Road, P. O. Box-19,

Barisal 


\section{Appendix-5}

\section{QUESTIONNAIRE ON ADOLESCENT FAMILY LIFE EDUCATION (AFLE) PROGRAMME}

Name of the Organization

Address:

Do you have any program with Girls/Boys?

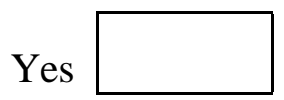

No

If yes, then go to a,b,c,d,

a) Age group

Girls

Boys

b) Starting date of the program

c) Duration

d) Working Area: Locations:

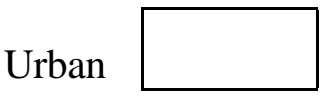

Rural

How was this program started?

Justification of the program

Objectives of the program

Activities of the program

Total Number of AFLE groups

Size of each group

- Do you involve/ motivate the parents/other members o Yes family in your program?

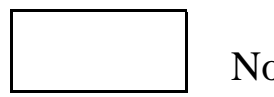

No

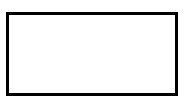

Was there any drop-out in your program

If yes, then specify

Yes

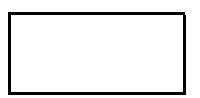

No

Percentage of drop-out (annually)

Reasons of drop-out

- What kinds of problems did you face (Programmatic, Financial, Others) to running the program?

- How did you solve the problem of your program?

- What have you achieved from the program?

. Comments and Recommendations

Name of the respondent

Date

Designation 